\title{
The Impact of Carbon Trading on Industry: Evidence from German Manufacturing Firms*
}

\author{
Sebastian Petrick $^{\dagger} \quad$ Ulrich J. Wagner ${ }^{\ddagger}$
}

March 28, 2014

\begin{abstract}
We estimate the causal impact of the EU Emissions Trading Scheme on manufacturing firms using comprehensive panel data from the German production census. Semiparametric matching estimators yield robust evidence that the policy caused treated firms to abate one-fifth of their $\mathrm{CO}_{2}$ emissions between 2007 and 2010 relative to non-treated firms. This reduction was achieved predominantly by improving energy efficiency and by curbing the consumption of natural gas and petroleum products, but not electricity use. We find no evidence that emissions trading lowered employment, gross output or exports of treated firms.
\end{abstract}

\footnotetext{
${ }^{*}$ We owe a debt of gratitude to Katrin Rehdanz for countless discussions and her generous support at all stages of this project. We thank the research data centre (FDZ) for granting us access to the AFiD data. We thank FDZ staff members Diane Zabel, Michael Rößner and, especially, Alexander Vogel of the Statistical Offices of the Länder in Bremen, Halle and Kiel, respectively, for expert advice regarding various AFiD modules and for technical help with the data matching and estimation. Staff at the Federal Statistical Office graciously provided information on various statistical products. We thank, without implicating, Max Auffhammer, Sylvain Chabé-Ferret, Jonathan Colmer, Ulrich Fahl, Holger Görg, Josh Linn, Ralf Martin, Justin McCrary, Mirabelle Muûls and Laure de Preux for helpful comments. Seminar audiences at Banco de España, Berkeley, Carlos III, Kiel, Mannheim and Stirling, as well as conference participants at EAERE 2013 and EEA 2013 provided useful feedback. Ulrich Wagner gratefully acknowledges financial support from the Spanish government under grants SEJ2007-62908 and ECO2012-31358. Views expressed in this paper are the personal opinion of the authors and do not reflect official positions held by Banco de España, by the FDZ, or by the Statistical Offices of the Länder.

${ }^{\dagger}$ Kiel Institute for the World Economy, Kiellinie 66, 24105 Kiel, Germany. E-mail: sebastian.petrick@ifw-kiel.de

${ }^{\ddagger}$ Corresponding author. Banco de España and Departamento de Economía, Universidad Carlos III de Madrid, Calle de Madrid 126, 28903 Madrid, Spain. E-mail: uwagner@eco.uc3m.es
} 


\section{Introduction}

In many classical areas of market failure, there has been a paradigm shift away from heavy-handed regulation toward policies that decentralize the decision of how to comply with a given regulatory objective. Preeminent examples are the privatization of state-owned natural monopolies and the liberalization of formerly monopolistic markets. Similarly, market-based instruments have gained momentum in the regulation of external effects. In pollution control, for example, the traditional quota-based approach has been increasingly replaced by markets where polluters can trade the right to pollute among each other. This approach, known as 'cap-and-trade' or 'emissions trading', is cost effective because market forces equalize marginal abatement costs across polluters.

Within the span of just two decades, emissions trading has evolved from an idea contemplated in academic circles to a widely implemented policy instrument 1 Since the 1980s, emissions trading systems for conventional pollutants have been implemented on an ever growing scale. The culmination of this remarkable development was reached in 2005 when the European Union (EU) launched the first mandatory carbon trading scheme in history $2^{2}$ The EU Emissions Trading Scheme (EU ETS) covers more than 2 billion tons of $\mathrm{CO}_{2}$ in 31 countries, making it the most significant market-based instrument of climate policy implemented to date, the first trans-boundary cap-and-trade system, and the world's largest carbon pricing experiment per se. Although the EU ETS is a prime candidate for evaluating the effectiveness and economic consequences of cap-and-trade in the real world, a recent literature survey concludes that causal evidence on these issues is still very scant, owing to the recency of the policy and a lack of suitable emissions data (Martin, Muûls and Wagner, 2013) $!^{3}$

This paper seeks to fill this gap. Using administrative panel data for

\footnotetext{
${ }^{1}$ The idea behind emissions trading has also been applied successfully to renewable resource management, establishing individually transferable quotas (ITQs) for fisheries.

${ }^{2}$ The 1997 Kyoto Protocol to the UN Framework Convention on Climate Change stipulated worldwide trading of carbon emissions between governments, which came into force in 2008.

${ }^{3}$ Much of the early academic research on the EU ETS is concerned with ex-ante impact assessments and based on CGE modeling or "theory with numbers" (e.g. Demailly and Quirion, 2008, 2006). Interim empirical assessments are based on surveys or interviews (e.g. McKinsey and Ecofys, 2006a b, Kenber, Haugen and Cobb, 2009).
} 
the universe of German manufacturing plants with at least 20 employees (approximately 50,000 per year), we estimate the causal impact of the EU ETS by combining a differences-in-differences approach with semiparametric matching techniques. The dataset is highly representative and covers a wide range of plant characteristics that we use as outcome variables and for matching. Its particular strength, for the purposes of this analysis, is the extraordinarily detailed information on energy consumption, which allows for very precise calculations of carbon emissions. The window of our analysis covers phase I of the EU ETS, which ran from 2005 until 2007 and the first three years of phase II up until 2010.

Our study focuses on Germany, Europe's largest economy and also its largest emitter. More than 1,900 of all EU ETS installations are based in Germany, accounting for approximately one fifth of total regulated $\mathrm{CO}_{2}$ emissions. The strong orientation of the German manufacturing sector toward export markets makes Germany a particularly interesting case for investigating the validity of widespread concerns that unilateral regulation of European firms leads to a loss of competitiveness in international product markets.

Our results indicate that the EU ETS did not reduce emissions in significant ways during its first phase, but it caused participating firms to substantially reduce their carbon emissions relative to untreated firms during phase II. This abatement was achieved through a reduction in the carbon intensity rather than through a reduced scale of production. While phase I saw some substitution of low-carbon for high-carbon fuels at treated firms, in phase II treated firms drastically reduced their use of all primary energy while maintaining constant their level of electricity consumption. We attribute this outcome to firms curbing onsite generation of heat as the pre-dominant way of reducing compliance costs. Qualitative evidence from telephone interviews with managers suggests that regulated firms optimized their use of process heat. In contrast, we find no evidence of major technological upgrades that would explain the reduction of carbon intensity.

We examine the competitiveness issue by estimating the impact of the EU ETS on employment, gross output, and exports of participating firms. Based on these estimates, we can reject the hypothesis that the EU ETS reduced gross output or exports. The impact on employment is insignificant 
in statistical and economic terms.

Our study is timely and contributes to the literature in several ways. The principal contribution is to provide robust evidence concerning the causal impact of world's largest emissions trading scheme on the manufacturing sector. This evidence not only is relevant for the policy debate in Europe but also informs policymakers in other parts of the world who are considering the adoption of regulatory instruments to curb carbon emissions. For instance, the EU ETS has served as a blueprint for similar policies in Australia, California, New Zealand, South Korea and other places where initiatives to establish carbon trading can be found at different stages of planning and implementation. From a broader perspective, the drive for more efficient regulation of market failures mentioned at the outset has made the need for empirical evaluation of regulatory instruments very salient. In this vein, our study adds to a broader literature on market-based regulation and, in particular, to a nascent empirical literature on cap-andtrade. While the bulk of this literature focuses on emissions trading among electricity producers (e.g. Ellerman et al., 2000), researchers have only just started to study cap-and-trade programs in the manufacturing sector (e.g. Fowlie, Holland and Mansur, 2012; Fowlie and Perloff, 2013).

The remainder of the paper is structured as follows. The next section describes the institutional details of the EU ETS, to the extent that they are relevant for the subsequent analysis, and reviews the related literature. Section 3 explains our research design and Section 4 describes the principle dataset. Section 5 presents our main results along with numerous robustness checks. Section 6 explores several channels of emission reductions. Section 7 concludes.

\section{Institutional background: The EU ETS}

\section{$2.1 \quad$ Scope}

The EU ETS is implemented as a classical cap-and-trade system for $\mathrm{CO}_{2}$ emissions. Participating firms receive emission permits - called EU Allowance Units (EUA) - that are fully tradable across firms in all participating countries. The EU ETS has been implemented in three phases. 
Phase I ran from 2005 to 2007 and served mainly as a trial phase to test the functioning of the system. Phase II coincided with the first commitment period of the Kyoto Protocol - 2008 to 2012 - which stipulated an 8\% reduction in GHG emissions compared to 1990 as the EU's Kyoto commitment under the burden sharing agreement. The current third phase of the EU-ETS will run until 2020. Independently of international efforts to curb greenhouse gas emissions beyond the EU, the ETS is the centerpiece of the EU's unilateral climate policy, which stipulates a $20 \%$ reduction of GHG emissions in 2020 relative to 1990. A comprehensive review of the history and structure of the EU ETS can be found in Ellerman, Marcantonini and Zaklan (2014).

According to the Emissions Trading Directive. 4 participation in the EU ETS is mandatory for all combustion installations with a rated thermal input of $20 \mathrm{MW}$ or more. This concerns mostly heat and power generation, regardless of the industry. In addition, industrial plants are regulated under the EU ETS if they specialize in certain industrial activities and exceed specific capacity thresholds. The activities defined in the Emissions Trading Directive correspond to four industry codes, namely "manufacture of paper and paper products" (WZ classification code 17), "manufacture of coke and refined petroleum products" (WZ19), "manufacture of other non-metallic mineral products" (WZ23, including i.a. manufacture of glass, ceramics, and cement), and "manufacture of basic metals" (WZ24) ${ }^{5}$ Henceforth, we shall refer to these industries as the "process regulated sectors". Beginning in 2012, emissions from other industries, such as aviation, have been included in the EU ETS as well.

\footnotetext{
${ }^{4}$ Directive 2009/29/EC of the European Parliament and of the Council amending Directive $2003 / 87 / \mathrm{EC}$ so as to improve and extend the greenhouse gas emission allowance trading scheme of the Community (2009) OJ L 140, 5.6.2009, p. 63-87 (Emissions Trading Directive).

${ }^{5}$ Note that the WZ classification system used in German Statistics corresponds to the ISIC codes (Rev. 4). From 2008 onwards, some activities have been added, e.g. from the chemical industry. The interested reader is referred to Appendix A.1 for more details.
} 


\subsection{Related literature}

In spite of the geographic, environmental, and financial scope of the EU ETS, little is known so far about the causal impacts of this policy (Martin, Muûls and Wagner, 2013). On the one hand, this lack of knowledge is due to the recency of this regulation; on the other hand, it results from the difficulty of obtaining representative firm-level data, especially for $\mathrm{CO}_{2}$ emissions. Early assessments by Ellerman and Buchner (2007, 2008); Ellerman, Convery and de Perthuis (2010); Anderson and Di Maria 2011) thus rely on more aggregate emissions data available at the sector level, and estimate counterfactual baseline emissions by extrapolating trends in these series. These studies find that emissions across all regulated sectors - energy and industry - declined by approximately $3 \%$ in Phase I and during the first two years of Phase II, relative to estimated business-as-usual emissions. The contribution of the industrial sector to this aggregate figure is not always clear. Using data for Germany, Ellerman and Feilhauer (2008) estimate that emissions by EU ETS participants fell by 5 percent, due to a 6.3 percent in industrial emissions and 4.1 percent emissions abatement in the power sector. A limitation of these studies is that the use of aggregate data does not support a causal attribution of the calculated emission reductions to the EU ETS.

Unlike emissions data, balance-sheet data on economic outcomes is readily available at the firm-level in databases such as AMADEUS (Bureau van Dijk, 1999-2008), including for pre-treatment years. These data have been used in conjunction with differences-in-differences estimators to evaluate the impact of the EU ETS on economic performance and competitiveness Anger and Oberndorfer, 2008; Commins et al., 2011; Chan, $\mathrm{Li}$ and Zhang, 2013). While there is a fair amount of heterogeneity across studies and outcomes, they do not support the view that the EU ETS had strong detrimental effects on the economic performance of regulated firms. In a large-scale survey of manufacturing firms in the EU, Martin et al. (2013a) find that regulated firms report a higher propensity to downsize their operations in response to future carbon pricing than non-ETS firms, but the effect is not large. Veith, Werner and Zimmermann (2009) and Bushnell, Chong and Mansur (2013) present evidence that stock owners of 
large EU ETS firms expected them to actually profit from higher permit prices as they could pass these on to product markets..$^{6}$

Recent research resorts to matching estimators as a way of credibly establishing identification of the causal impact of emissions trading on firm behavior. Fowlie, Holland and Mansur (2012) combine matching and differences-in-differences to evaluate the impact of the RECLAIM program on $\mathrm{NO}_{x}$ emissions of industrial emitters in Southern California. For the EU ETS, Abrell, Ndoye and Zachmann (2011) apply nearest-neighbor matching to a large sample of European firms and find that the policy caused a small but significant decrease in employment of 0.9 percent between 2004 and 2008. Using data on patent applications filed at the European Patent Office, Calel and Dechezleprêtre (2012) estimate that the EU ETS is responsible for an additional 188 low-carbon patents, which corresponds to an increase of approximately $8.1 \%$ for ETS firms. Unpublished work by Wagner et al. (2013) uses plant-level data from the French manufacturing sector to construct matching estimators of the impact of the EU ETS. These authors find that the EU ETS had no impact in phase I but reduced both emissions and employment during the first half of the second trading phase.

\section{Research Design}

It is useful to distinguish between the direct and indirect effects of the EU ETS on manufacturing firms. As a rule, conventional power generation in Europe is subject to cap-and-trade. As the power sector passes the opportunity cost of emission permits to consumers in the form of higher prices (Sijm, Neuhoff and Chen, 2006, Zachmann and Von Hirschhausen, 2008; Fabra and Reguant, 2014), there is an indirect impact on manufacturing through higher electricity prices. In addition, by establishing a uniform carbon price, the ETS has a direct impact on those firms participating in it. The parameter we seek to identify and estimate is the average effect of the EU ETS on participating firms, over and above any indirect effect the EU ETS may have had on the entire manufacturing sector. Similar

\footnotetext{
${ }^{6}$ In contrast, an event study of the $\mathrm{NO}_{\mathrm{x}}$ Budget Trading Program by Linn (2010) shows that cap-and-trade reduced profits of power generators in the US.
} 
to Fowlie, Holland and Mansur (2012), we resort to a matching approach that exploits both the longitudinal structure of our dataset and the rich information on firm characteristics to recover a consistent estimate of the treatment effect 7

\subsection{Difference-in-difference matching estimator}

In line with the potential outcome framework, denote by $Y_{i}(1)$ the outcome at firm $i$ when subject to the ETS and by $Y_{i}(0)$ the outcome when the plant is not subject to the ETS. Let $D_{i}$ denote the treatment indicator, and subscripts $t^{\prime}$ and $t$ denote pre- and post-treatment periods, respectively. $X$ is a set of observable covariates. We are interested in the average treatment effect on the treated (ATT)

$$
\alpha_{A T T}=E\left(Y_{i t}(1)-Y_{i t}(0) \mid X, D=1\right) .
$$

The fundamental evaluation problem arises because $Y_{i t}(0)$ is unobserved for the treated. The matching approach to solving this problem consists of imputing $Y_{i t}(0)$ using outcomes for untreated firms that are observationally equivalent to the treated firm. The ATT can then be estimated from the sample equivalent of the expression $E\left(Y_{i t}(1) \mid X, D=1\right)-$ $E(Y(0) \mid X, D=0)$, assuming conditional independence between outcomes and treatment status, $\left(y_{i t^{\prime}}(0), y_{i t^{\prime}}(1)\right) \perp D \mid X$. In view of the participation thresholds for the EU ETS, this unconfoundedness assumption appears too demanding in the policy context considered here. However, the ATT can be identified under a weaker such assumption by bringing in longitudinal information and focusing on differences-in-differences (DD) of outcomes. In particular, Heckman, Ichimura and Todd (1997) suggest to estimate the

\footnotetext{
${ }^{7}$ In principle, the threshold-based eligibility rules of the EU ETS could be exploited in a regression discontinuity design (RDD). As shown in Appendix A.1, thresholds are tied to technical characteristics such as the production capacity of a particular product in process-regulated industries, and the rated thermal input of combustion facilities. German law requires firms to submit this information to the regulator when applying for an operating permit, but only large facilities have to make it public. For instance, while the participation threshold for combustion installations is $20 \mathrm{MW}$ rated thermal input, the application procedure is public only for combustion installations with at least 50 MW. In process-regulated sectors, the participation threshold often coincides with the one for publication. Therefore, RDD is not feasible.
} 
ATT from the sample analogues of the population moments

$$
D_{t, t^{\prime}}(X)=E\left(Y_{i t}(1)-Y_{i t^{\prime}}(0) \mid X, D=1\right)-E\left(Y_{i t}(0)-Y_{i t^{\prime}}(0) \mid X, D=0\right) .
$$

To implement this, they propose a semiparametric conditional DD matching estimator

$$
\hat{\alpha}=\frac{1}{N_{1}} \sum_{i \in I_{1}}\left\{\left(Y_{i t}(1)-Y_{i 0}(0)\right)-\sum_{k \in I_{0}} W_{N_{0}, N_{1}}(i, k) \cdot\left(Y_{k t}(0)-Y_{k 0}(0)\right)\right\}
$$

where $I_{1}$ is the set of $N_{1}$ ETS participants and $I_{0}$ is the set of $N_{0}$ nonparticipants. The weight $W_{N_{0}, N_{1}}(i, k)$ with $\sum_{k \in I_{0}} W_{N_{0}, N_{1}}(i, k)=1$ determines how strongly the counterfactual observation $k$ contributes to the estimated treatment effect. A control plant is weighted more strongly the more similar - in covariate space - it is to the treated facility. The specific weighting function is determined by the matching algorithm 8

To pair treated and control firms, we specify weights $W_{N_{0}, N_{1}}(i, k)$ that combine nearest neighbor (NN) matching algorithms and propensity score matching (cf. Rosenbaum and Rubin, 1983). The propensity score, denoted $p_{i}$, predicts a firm's probability of participating in the EU ETS, $P(X) \equiv \operatorname{Pr}(D=1 \mid X)$, for given observable characteristics $X$. We estimate the propensity score in a probit regression of a firm's treatment status on a vector of firm characteristics $\mathbf{x}$. Under one-to-one NN matching, the outcome of a treated firm is compared to the outcome of the non-treated firm whose propensity score is closest to that of the treated firm. Under one-to-many NN matching, the counterfactual outcome is a simple average of the outcomes at all neighboring non-treated firms.

Below we also report the results from an alternative approach to estimating the ATT, based on a combination of weighting and regression.

${ }^{8}$ To be precise, we will estimate an averaged version of this parameter

$$
M(S)=\frac{\int_{S} E\left(Y_{1}-Y_{0} \mid X, D=1\right) d F(X \mid D=1)}{\int_{S} d F(X \mid D=1)}
$$

where $S$ is a subset of the support of $X$ given $D=1$ (Heckman, Ichimura and Todd, 1997). 
Specifically, we perform OLS on the weighted DD equation

$$
\Delta y_{i t}=\text { constant }+\alpha_{A T T}^{R} D_{i}+x_{i t}^{\prime} \beta+\epsilon_{i t}
$$

where the propensity score is used to reweight the distribution of treated and non-treated firms. Contrary to NN matching, weighted outcomes of all untreated firms are used to construct the counterfactual. While treated firms enter the regression with a weight of one, the weights for the untreated firms $\frac{p_{k}}{1-p_{k}}$ are based on the estimated propensity score and ensure that the distribution of the control variables is approximately equal for both groups. Including the covariates $x$ used for estimating the propensity score in (4) is redundant if the propensity score is estimated consistently. Hence, the reweighting estimator is double-robust in the sense that it is consistent if either the propensity score model is correctly specified or the outcome is linear in the explanatory variables (Hirano and Imbens, 2001; Imbens, 2004; Lunceford and Davidian, 2004; Busso, DiNardo and McCrary, 2013).

\subsection{Identifying assumptions}

The matching estimators in (3) and (4) identify the ATT under the assumption (Heckman, Ichimura and Todd, 1998)

$$
E\left(Y_{i t}(0)-Y_{i t^{\prime}}(0) \mid P(X), D=1\right)=E\left(Y_{i t}(0)-Y_{i t^{\prime}}(0) \mid P(X), D=0\right)
$$

This is considerably weaker than conditional independence 9 In the given application, it means that counterfactual trends in outcomes in ETS firms must not be systematically different from those in the group of matched control firms. A further identifying assumption is that matching is performed on a common support $X \in S(P(X) \mid D=1)$ where the distributions of covariates in the treatment and control groups overlap. Finally, we must rule out the possibility that the treatment effect spills over from the treated to the untreated. In the program evaluation literature, this assumption is referred to as the Stable Unit Treatment Value Assumption (SUTVA). An

\footnotetext{
${ }^{9}$ Using experimental data on a job training program for comparison, Heckman, Ichimura and Todd (1997) test different variants of the unconfoundedness assumptions. While assumption (5) cannot be rejected, stronger assumptions are indeed rejected by the data.
} 
immediate concern in this regard is with spillovers between treated and untreated plants within the firm. To circumvent this problem, we conduct the analysis at the firm level, thereby internalizing such spillovers 10 If firms used to construct the counterfactual are affected by the treatment, their post-treatment outcomes, and thus also the estimated treatment effect, will be biased.

While the common support assumption is directly testable, unfoundedness and SUTVA are not. We will evaluate the plausibility of these assumptions in Section 5.2 below.

\section{Data}

\subsection{Data sources}

Our principal dataset is the "AFiD-Betriebspanel" from Germany, which is available to approved researchers at the Research Data Centres maintained by the German Federal Statistical Office and the statistical offices of the German Länder. The AFiD panel currently comprises annual data from 1995 until 2010 on the universe of German manufacturing plants with more than 20 employees 11 The dataset covers approximately 50,000 plants per year and contains information on a wide range of economic variables such as employment, gross output, investment, and exports. These data are collected as part of the monthly production surveys administered by the German statistical office.

Energy use is a central aspect of this study. For the first half of the panel (1995-2002), this information is available for the main fuel types, i.e., coal, gas, electricity and oil. From 2003 onwards, the information comes from a separate but also mandatory survey covering energy consumption for more than 15 different fuel types, electricity generation on site and electricity trading (see Petrick, Rehdanz and Wagner, 2011, for details). This information allows us to calculate plant-level carbon emissions and

\footnotetext{
${ }^{10}$ Aggregating plants to the firm level also circumvents the problem that prices in intra-firm trade might differ from market prices.

${ }^{11}$ Smaller plants are included as well if they belong to a firm with at least 20 employees. From 2007 onwards, the cutoff is 50 employees. The earliest period used in this paper is 1998 .
} 
carbon intensity of production with unprecedented accuracy.

The list of treated plants is available from the CITL, the official registry of the EU ETS. We use a combination of trade registry numbers, VAT numbers and Bureau von Dijk identifiers to match information on EU ETS participation to firm identifiers in the AFiD panel 12 Starting with a complete list of German trading account holders, we first drop hospitals, universities, and other accounts that are clearly not part of the manufacturing sector. Of the remaining 1,879 facilities, 1,658 (88\%) were successfully matched to AFiD firms. The other 221 account holders could not be matched to any entry in the official firm register at the Statistical Offices. Most likely, this is because small plants are not sampled in the AFiD panel, or because the account holder is not a manufacturing firm. Given these circumstances, the effective matching rate is likely to be considerably higher than $88 \%$.

\subsection{Descriptive statistics}

Because we are interested in the firm-level impact of the EU ETS, we aggregate all plant-level variables on economic performance and energy mix up to the firm level. Table 1 summarizes the firm characteristics that are central to our analysis, using observations for the year 2003. Panel A reports summary statistics for the full sample after cutting off the top and bottom one percent of the outcome distribution. ${ }^{13}$ Approximately one percent of the remaining 41,000 firms participate in the EU ETS. Panel B summarizes the characteristics of these firms ${ }^{14}$ Upon comparing panels A and B, we see that ETS participants are considerably larger, more prone to export, and paying higher wages than firms in the full sample. This highlights the extent of selection on observable firm characteristics.

To construct a meaningful control group for the ETS participants from the large set of untreated firms, we resort to semi-parametric matching techniques discussed in Section 4.3 below. Panel $\mathrm{C}$ of Table 1 summarizes

\footnotetext{
${ }^{12}$ The matching could not be done at the plant level as there is no concordance table between AFiD plant identifiers and the available identifiers in the CITL. Confidentiality rules prevented us from matching on installation names.

${ }^{13}$ This is meant to minimize the influence of outliers in the subsequent estimations.

${ }^{14}$ Confidentiality restrictions imposed by the data provider prevent us from reporting arithmetic means by treatment status, but we report $t$-statistics from a test of equality in Panel A of Table2.
} 
Table 1: Summary statistics for outcome variables and covariates in 2003

\begin{tabular}{|c|c|c|c|c|c|c|}
\hline Variable & $\begin{array}{r}(1) \\
\text { Mean }\end{array}$ & $\begin{array}{r}(2) \\
\text { Std. Dev. }\end{array}$ & $\begin{array}{r}(3) \\
\text { p10 }\end{array}$ & $\begin{array}{r}(4) \\
\text { p50 }\end{array}$ & $\begin{array}{r}(5) \\
\text { p90 }\end{array}$ & $\begin{array}{r}(6) \\
\mathrm{N}\end{array}$ \\
\hline \multicolumn{7}{|l|}{ A. Full sample (mid-98\%) } \\
\hline $\begin{array}{l}\mathrm{CO}_{2} \text { emissions from energy }(\mathrm{t}) \\
\mathrm{CO}_{2} \text { intensity }(\mathrm{g} / € 1000) \\
\text { Employees } \\
\text { Gross output }(€ 1000) \\
\text { Exports }(€ 1000) \\
\text { Export share of output } \\
\text { Average wage rate }(€)\end{array}$ & $\begin{array}{r}1,912 \\
108,581 \\
104 \\
17,597 \\
4,978 \\
0.16 \\
28,649\end{array}$ & $\begin{array}{r}5,618 \\
143,612 \\
158 \\
38,223 \\
15,776 \\
0.22 \\
9,681\end{array}$ & $\begin{array}{r}35 \\
8,250 \\
22 \\
1,435 \\
0 \\
0.00 \\
15,998\end{array}$ & $\begin{array}{r}314 \\
62,793 \\
49 \\
5,299 \\
198 \\
0.04 \\
28,458\end{array}$ & $\begin{array}{r}4,098 \\
248,907 \\
233 \\
40,580 \\
11,542 \\
0.53 \\
41,213\end{array}$ & $\begin{array}{l}40,834 \\
40,709 \\
40,325 \\
40,204 \\
40,947 \\
40,931 \\
40,409\end{array}$ \\
\hline \multicolumn{7}{|l|}{ B. ETS participants } \\
\hline $\begin{array}{l}\mathrm{CO}_{2} \text { emissions from energy }(\mathrm{t}) \\
\mathrm{CO}_{2} \text { intensity }(\mathrm{g} / € 1000) \\
\text { Employees } \\
\text { Gross output }(€ 1000) \\
\text { Exports }(€ 1000) \\
\text { Export share of output } \\
\text { Average wage rate }(€)\end{array}$ & $\begin{array}{l}\cdot \\
. \\
. \\
. \\
. \\
. \\
.\end{array}$ & $\begin{array}{r}795,888 \\
1,449,921 \\
11,370 \\
4,191,998 \\
2,853,722 \\
0.27 \\
9,393\end{array}$ & $\begin{array}{r}6,146 \\
84,392 \\
52 \\
6,748 \\
324 \\
0.00 \\
26,729\end{array}$ & $\begin{array}{r}51,716 \\
670,420 \\
388 \\
95,703 \\
28,064 \\
0.29 \\
37,214\end{array}$ & $\begin{array}{r}457,851 \\
2,604,891 \\
4,103 \\
1,125,042 \\
647,477 \\
0.70 \\
48,408\end{array}$ & $\begin{array}{l}408 \\
413 \\
433 \\
430 \\
369 \\
408 \\
408\end{array}$ \\
\hline \multicolumn{7}{|c|}{ C. Non-ETS participants (matched sample) } \\
\hline $\begin{array}{l}\mathrm{CO}_{2} \text { emissions from energy }(\mathrm{t}) \\
\mathrm{CO}_{2} \text { intensity }(\mathrm{g} / € 1000) \\
\text { Employees } \\
\text { Gross output }(€ 1000) \\
\text { Exports }(€ 1000) \\
\text { Export share of output } \\
\text { Average wage rate }(€)\end{array}$ & $\cdot$ & $\begin{array}{r}372,759 \\
1,786,216 \\
1,994 \\
759,593 \\
323,759 \\
0.25 \\
9,283\end{array}$ & $\begin{array}{r}510 \\
37,991 \\
42 \\
5,728 \\
936 \\
0.00 \\
25,767\end{array}$ & $\begin{array}{r}12,047 \\
155,349 \\
208 \\
64,809 \\
21,537 \\
0.28 \\
39,210\end{array}$ & $\begin{array}{r}891,534 \\
1,769,886 \\
4,384 \\
825,606 \\
802,049 \\
0.64 \\
49,010\end{array}$ & $\begin{array}{l}278 \\
283 \\
296 \\
293 \\
248 \\
278 \\
278\end{array}$ \\
\hline
\end{tabular}

Notes: $\mathrm{CO}_{2}$ intensity in terms of gross output $(\mathrm{g} / € 1000)$. Means for matched sample cannot be obtained for reasons of data privacy.

Source: Research Data Centres of the Federal Statistical Office and the Statistical Offices of the Länder (2012): AFiD-Panel Industriebetriebe, 2005-2010, own calculations. 
Table 2: Pre-treatment outcomes in the matched sample

\begin{tabular}{|c|c|c|c|c|c|c|}
\hline \multirow[b]{3}{*}{ Variable } & \multicolumn{6}{|c|}{ Null hypothesis: Equality of pre-treatment outcomes } \\
\hline & \multicolumn{3}{|c|}{ A. Levels } & \multicolumn{3}{|c|}{ B. Trends } \\
\hline & $p$-value & $\begin{array}{l}\text { Num } \\
\text { treated }\end{array}$ & $\begin{array}{l}\text { er of } \\
\text { controls }\end{array}$ & $p$-value & $\begin{array}{l}\text { Num } \\
\text { treated }\end{array}$ & $\begin{array}{l}\text { er of } \\
\text { controls }\end{array}$ \\
\hline $\mathrm{CO}_{2}$ emissions & 0.0911 & 408 & 278 & 0.0505 & 405 & . \\
\hline $\mathrm{CO}_{2}$ intensity & 0.0197 & 413 & 283 & 0.2025 & 409 & . \\
\hline Gross output & 0.0054 & 430 & 293 & 0.3141 & 428 & . \\
\hline Employees & 0.0051 & 433 & 296 & 0.6177 & 431 & . \\
\hline Exports & 0.0073 & 369 & 248 & 0.1047 & 336 & . \\
\hline Export share & 0.1634 & 408 & 278 & 0.2483 & 406 & . \\
\hline Average wage rate & 0.0086 & 408 & 278 & 0.0603 & 285 & . \\
\hline
\end{tabular}

Notes: Number of control firms for matched sample are not reported for confidentiality reasons. Source: Research Data Centres of the Federal Statistical Office and the Statistical Offices of the Länder (2012): AFiD-Panel Industriebetriebe, 2005-2010, own calculations.

the characteristics of the control firms selected by a one-to-one NN matching algorithm. 14 While matching likens the distribution of firm characteristics to the distribution among treated firms, a test of equality of means still rejects at the 5-percent significance level for a number of outcome variables (see panel A of Table 2). Thus, assuming conditional independence between outcomes and treatment status seems too restrictive in the given policy context. The identifying assumption (5) adopted here posits conditional independence between changes in the outcome variables and treatment status. While untestable, this assumption is more plausible if outcome trends are parallel in the years leading up to the policy intervention. A visual inspection of these trends - graphed in Figure C.1 of the Appendix - confirms this. Moreover, panel B of Table 2 reports the results of a $t$-test of equal pre-treatment trends in the treatment and control group, based on logged differences in outcome variables between 2002 and 2003. We cannot reject the Null hypothesis at the 5-percent significance level for any of the outcome variables. Because the test statistics for emissions and the average wage rate are statistically significant at the 10-percent significance level, we dedicate ample space in Section 5.2 below to exploring the robustness of our estimation results to alternative conditioning strategies. Among other things, we shall show that the estimated treatment effects are robust to matching directly on pre-treatment growth rather than the level of the outcome variable. 


\subsection{Matching}

We use propensity score matching techniques to construct counterfactuals for each treated firm. We estimate the propensity score using a probit regression of treatment status on a rich set of observable pre-treatment characteristics, including $\mathrm{CO}_{2}$ emissions, gross output, export share of output, number of employees, and the average wage rate, as well as the squares of all of these variables. We also include dummies that control for the twodigit industry (WZ classification) and for the state (Bundesland) wherein the firm is located. The results are reported in Table C.1 in the Appendix.

As mentioned above, participation rules under the EU ETS follow two basic principles. On the one hand, certain industrial processes are regulated directly, with process-specific capacity thresholds determining participation ${ }^{15}$ On the other hand, combustion installations with a rated thermal input of $20 \mathrm{MW}$ or more are subject to emissions trading, regardless of the industry. On account of the difference in treatment assignment between these two groups, we partition the sample in process-regulated industries vs. all other industries, and require sharp overlay of NN matches with respect to these strata. ${ }^{16}$ While treated firms are more abundant in process regulated industries than in all other industries (260 compared to 188), the total number of firms is considerably larger in the other stratum $(24,947$ compared to 2,486$)$.

To find suitable matches for the treated firms among the untreated firms, we perform NN matching based on the predicted propensity scores. ${ }^{17}$ Our preferred estimates are based on one-to-one NN matching, i.e. we match to each treated firm the untreated firm with the minimal distance in the propensity scores. For robustness, we also present estimates based on one-to-twenty NN matching where a synthetic counterfactual for each

\footnotetext{
${ }^{15}$ For more information on process regulated industries, see Section 2 above and Section A.1 of the appendix.

${ }^{16}$ For example, this means that a steel-producing firm (process regulated) cannot be matched to a firm in the chemical industry, but it can be matched either to an untreated steel-producing firm or to a paper mill (also process regulated). Because the propensity score includes sector dummies, matching across 2-digit sectors is not likely to occur, however. In one of the robustness checks, we rule out such matches altogether and find that this has very little impact on our qualitative findings.

${ }^{17}$ We use NN matching with replacement, i.e. each firm in the control group can be used more than once as a match.
} 
treated firm is constructed as the mean outcome calculated among the twenty untreated firms with the most similar propensity score. Oversampling control firms is known to reduce the variance of the estimate, though potentially at the cost of a higher bias. The reweighted OLS estimator described in (4) uses the complete set of non-treated firms with a weighting scheme that is based on the same covariates as the propensity score.

In Section 5.2 below, we demonstrate that our main results are robust to a series of alternative choices for the set of conditioning variables, the base year for matching, the level of stratification, and the matching algorithm.

\section{$5 \quad$ Results}

\subsection{Main Results}

The principal objective of the EU ETS is to reduce carbon dioxide emissions in Europe. Estimating the average treatment effect of the EU ETS on emissions of treated firms tells us how successful the policy has been at curbing $\mathrm{CO}_{2}$ emissions in the German manufacturing sector. Table 3 displays the ATT estimates for $\mathrm{CO}_{2}$ emissions. Columns (1) and (2) report coefficients estimated with one-to-one and one-to-twenty nearest-neighbor matching, respectively. Column (3) reports the coefficient estimated using the reweighted OLS estimator from (4). Columns (4) and (5) report numbers of treated and control observations for nearest neighbor matching. 18 Panel A reports the log change in $\mathrm{CO}_{2}$ emissions that can be causally attributed to participation in the EU ETS, whereas panel B reports the causal effect in terms of the log change in the carbon intensity of output. The estimates are reported separately for phase I (2005-2007) and the first half of phase II (2008-2010).

A clear pattern emerges from panel A. The point estimates for the first trading phase are positive, very close to zero and lack statistical significance. We thus cannot reject the Null hypothesis that treated firms conducted no abatement in the first phase. In contrast, we see strong evidence that phase II of the EU ETS caused treated firms to reduce their emissions

\footnotetext{
${ }^{18}$ Note that the double-robust reweighting estimator (OLS w/R) covers more firms because control firms outside the region of common support are included as well.
} 
Table 3: Impact on $\mathrm{CO}_{2}$ emissions

\begin{tabular}{|c|c|c|c|c|c|}
\hline & (1) & $(2)$ & (3) & (4) & $(5)$ \\
\hline & Esti & nation Algo & ithm & Num & per of \\
\hline & NN (1:1) & NN $(1: 20)$ & OLS w/R & Treated & Controls \\
\hline \multicolumn{6}{|c|}{ A. $\mathrm{CO}_{2}$ emissions: $\Delta \ln \left(\mathrm{CO}_{2}\right)$} \\
\hline Phase I & $\begin{array}{c}0.00 \\
(0.03)\end{array}$ & $\begin{array}{c}0.02 \\
(0.02)\end{array}$ & $\begin{array}{c}0.03 \\
(0.03)\end{array}$ & 452 & 27,710 \\
\hline Phase II & $\begin{array}{c}-0.28^{* *} \\
(0.05)\end{array}$ & $\begin{array}{c}-0.25^{* *} \\
(0.03)\end{array}$ & $\begin{array}{c}-0.26^{* *} \\
(0.03)\end{array}$ & 408 & 23,908 \\
\hline \multicolumn{6}{|c|}{ B. $\mathrm{CO}_{2}$ intensity of gross output: $\Delta \ln \left(\frac{\mathrm{CO}_{2}}{G O}\right)$} \\
\hline Phase I & $\begin{array}{c}0.04 \\
(0.05)\end{array}$ & $\begin{array}{c}0.03 \\
(0.03)\end{array}$ & $\begin{array}{l}0.05^{*} \\
(0.03)\end{array}$ & 451 & 27,637 \\
\hline Phase II & $\begin{array}{c}-0.18^{* *} \\
(0.05)\end{array}$ & $\begin{array}{c}-0.20^{* *} \\
(0.04)\end{array}$ & $\begin{array}{c}-0.30 * * \\
(0.03)\end{array}$ & 412 & 23,742 \\
\hline \multicolumn{6}{|c|}{$\begin{array}{l}\text { Notes: } \mathrm{NN}(1: 1) \text { and } \mathrm{NN}(1: 20) \text { denote nearest neighbor matching with one and } 20 \\
\text { neighbors, respectively. OLS } \mathrm{w} / \mathrm{R} \text { denotes the reweighted OLS estimator. Standard } \\
\text { errors in parenthesis. }{ }^{* * *} \mathrm{p}<0.01,{ }^{* *} \mathrm{p}<0.05,{ }^{*} \mathrm{p}<0.1 \text {. Source: Research Data Cen- } \\
\text { tres of the Federal Statistical Office and the Statistical Offices of the Länder }(2012) \\
\text { AFiD-Panel Industriebetriebe, } 1998-2010 \text {, own calculations. }\end{array}$} \\
\hline
\end{tabular}

by a substantial margin, in the order of 25 to 28 percentage points more than non-treated firms. This finding is statistically significant at the $5 \%$ level and robust across specifications.

The impact on carbon intensity, reported in Panel B, closely mimics the overall effect on emissions. Carbon intensity remains almost unchanged throughout phase I, although the point estimates are somewhat larger than for emissions and the reweighting estimator actually yields an increase by 5 percentage points at the 10 percent significance level. However, in phase II, carbon intensity fell between 18 and 30 percentage points faster at EU ETS firms than at the control firms, and again this effect is statistically significant at the 5 percent level. This result suggests that firms responded to the introduction of the EU ETS mainly by adjusting intensity, not scale.19

We investigate this further by examining changes in output and employment. Panel A of Table 4 reports the average treatment effects of the EU ETS on employment. The point estimates for employment range from

\footnotetext{
${ }^{19}$ Further results reported in Table C.5 in the appendix show that both processregulated and all other EU ETS firms reduced their carbon emissions. The response is slightly stronger in the former.
} 
Table 4: Impact on employment, gross output and exports

\begin{tabular}{|c|c|c|c|c|c|}
\hline & (1) & $(2)$ & $(3)$ & $(4)$ & $(5)$ \\
\hline & \multicolumn{3}{|c|}{ Estimation Algorithm } & \multicolumn{2}{|c|}{ Number of } \\
\hline & $\mathrm{NN}(1: 1)$ & NN $(1: 20)$ & OLS w/R & Treated & Controls \\
\hline \multicolumn{6}{|c|}{ A. Employees $(\Delta \ln L)$} \\
\hline Phase I & $\begin{array}{c}0.00 \\
(0.02)\end{array}$ & $\begin{array}{l}-0.02 \\
(0.01)\end{array}$ & $\begin{array}{l}-0.02 \\
(0.01)\end{array}$ & 454 & 28,396 \\
\hline Phase II & $\begin{array}{c}0.03 \\
(0.02)\end{array}$ & $\begin{array}{c}0.01 \\
(0.01)\end{array}$ & $\begin{array}{c}0.01 \\
(0.01)\end{array}$ & 433 & 24,237 \\
\hline \multicolumn{6}{|c|}{ B. Gross output $(\Delta \ln G O)$} \\
\hline Phase I & $\begin{array}{c}0.01 \\
(0.03)\end{array}$ & $\begin{array}{c}0.01 \\
(0.02)\end{array}$ & $\begin{array}{c}0.01 \\
(0.02)\end{array}$ & 449 & 28,465 \\
\hline Phase II & $\begin{array}{c}0.07^{* * *} \\
(0.03)\end{array}$ & $\begin{array}{c}0.05^{* * *} \\
(0.02)\end{array}$ & $\begin{array}{c}0.04^{* *} \\
(0.02)\end{array}$ & 430 & 24,240 \\
\hline \multicolumn{6}{|c|}{ C. Exports: $\Delta \ln (X)$} \\
\hline Phase I & $\begin{array}{c}0.06 \\
(0.06)\end{array}$ & $\begin{array}{c}0.10^{* *} \\
(0.04)\end{array}$ & $\begin{array}{c}0.11^{* * *} \\
(0.04)\end{array}$ & 371 & 17,864 \\
\hline Phase II & $\begin{array}{c}0.18^{* * *} \\
(0.06)\end{array}$ & $\begin{array}{c}0.09^{* *} \\
(0.04)\end{array}$ & $\begin{array}{l}0.07^{*} \\
(0.04)\end{array}$ & 348 & 15,463 \\
\hline
\end{tabular}

Notes: $\mathrm{NN}(1: 1)$ and $\mathrm{NN}(1: 20)$ denote nearest neighbor matching with one and 20 neighbors, respectively. OLS w/R denotes the reweighted OLS estimator. ${ }^{* * *} p<0.01$, ${ }^{* *} p<0.05,{ }^{*} p<0.1$.

Source: Research Data Centres of the Federal Statistical Office and the Statistical Offices of the Länder (2012): AFiD-Panel Industriebetriebe, 1998-2010, own calculations. 
-0.02 to $0.01 \log$ points. None of the coefficient estimates is statistically significant at the $5 \%$ level. 0 Hence our results do not support fears that putting a price on carbon comes at the expense of domestic job destruction.

The estimated impact of the EU ETS on gross output, reported in Panel B of Table 4, is small and insignificant in phase I. In phase II, however, we estimate that the EU ETS increased gross output at regulated firms by a statistically significant amount of between 4 and 7 percent. We thus reject the hypothesis that the EU ETS caused firms to reduce the scale of production. The positive effect on gross output is consistent with both firms producing more and charging higher prices. Unfortunately, we cannot distinguish further between these two responses for lack of a measure of physical output.

If firms did in fact increase prices to recoup the costs of carbon trading, this means that their competitiveness is not jeopardized at least in the domestic product market. The concern with unilateral regulations is, however, that regulated firms lose competitiveness in international markets where they compete with unregulated firms from overseas. To shed light on this, we estimate the ATT of the EU ETS on total exports, reported in panel $\mathrm{C}$ of Table 4 . The point estimates range from 0.06 to 0.11 for phase I and from 0.07 to 0.18 for phase II. The precision of these estimates varies across specifications, with only four out of six being statistically significant at the 5 percent level or better. In these cases, we can reject the hypothesis that the EU ETS caused regulated firms to reduce their overall exports. Again, it is not clear whether the increase in exports reflects an increase in the volume of shipments or a price increase, or both ${ }^{21}$

\subsection{Robustness checks}

The results reported above show that the point estimates are quite robust to increasing the number of control firms in NN matching algorithms from one to twenty, as well as to using a linear regression approach with reweighting.

\footnotetext{
${ }^{20}$ The phase-I coefficients for employment in columns 2 and 3 are -0.166 and -0.019 with standard errors 0.013 and 0.013 , respectively.

${ }^{21}$ Table C.7 in the appendix reports the ATT estimates for the share of exports in gross output. The point estimates in panel A range from 0.03 to 0.07 and the Null hypothesis of no impact on the export share is rejected only once. Robustness checks reported in panel $\mathrm{B}$ and $\mathrm{C}$ yield similar findings.
} 
Figure 1: NN (1:1) estimates when matching on pre-treatment trends

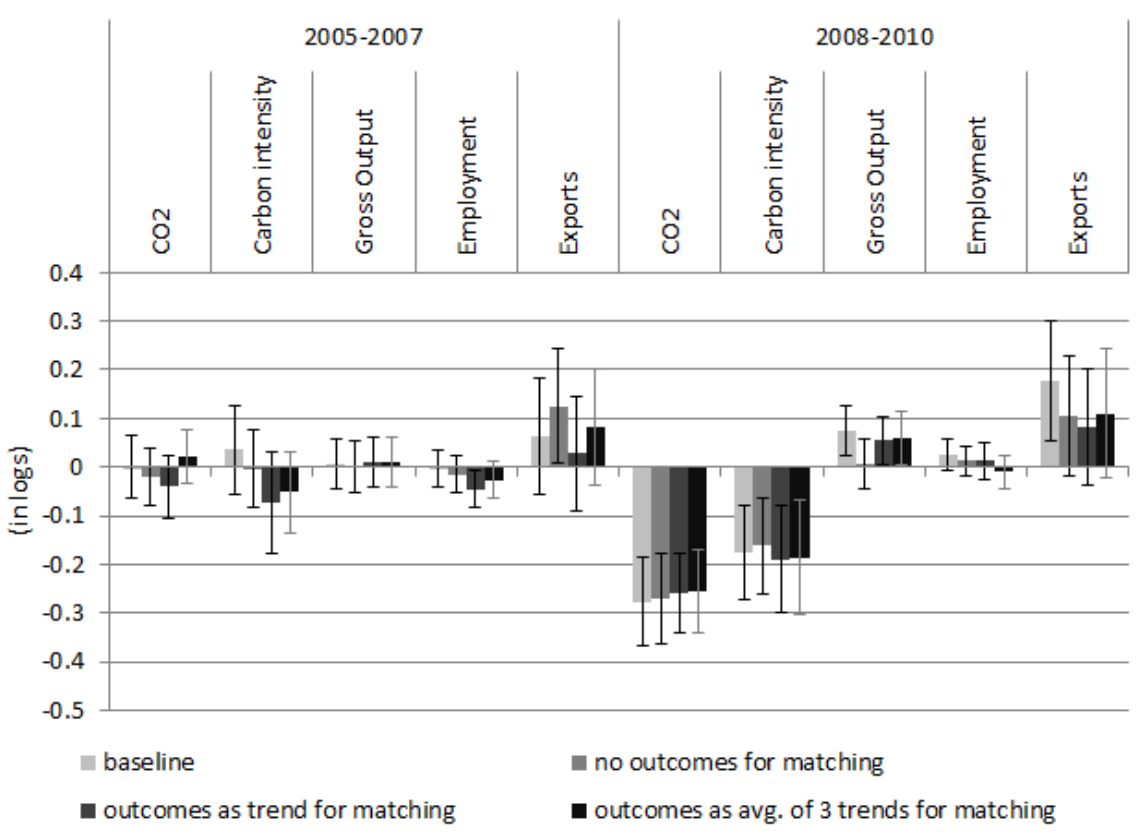

Notes: Error bars represent the 95 \% confidence interval. Source: Research Data Centres of the Federal Statistical Office and the Statistical Offices of the Länder (2012): AFiD-Panel Industriebetriebe, 19982010, own calculations.

Nonetheless, consistent estimation of the ATTs above is predicated on a number of identifying assumptions. This section provides further evidence that our results are robust to a number of challenges to the identifying assumptions.

\section{Unconfoundedness}

Unconfoundedness - i.e., the assumption in (5) that the counterfactual trend in the outcome variable is not systematically different between treatment and control groups - is not directly testable, so we assess its credibility from a number of different angles. We start by examining the pre-treatment trends across treatment groups. Because unconfoundedness assumes parallel trends in the counterfactual scenario, it is more credible if these trends are parallel already in the years prior to the intervention. Figure C.1 in the appendix plots the trends for the outcome variables by treatment status, showing in fact parallel trends prior to treatment. Moreover, panel B of Table 2 shows that a formal test of equality of pre-treatment trends does 
Figure 2: NN (1:1) estimates with exact matching on 2-digit industry code

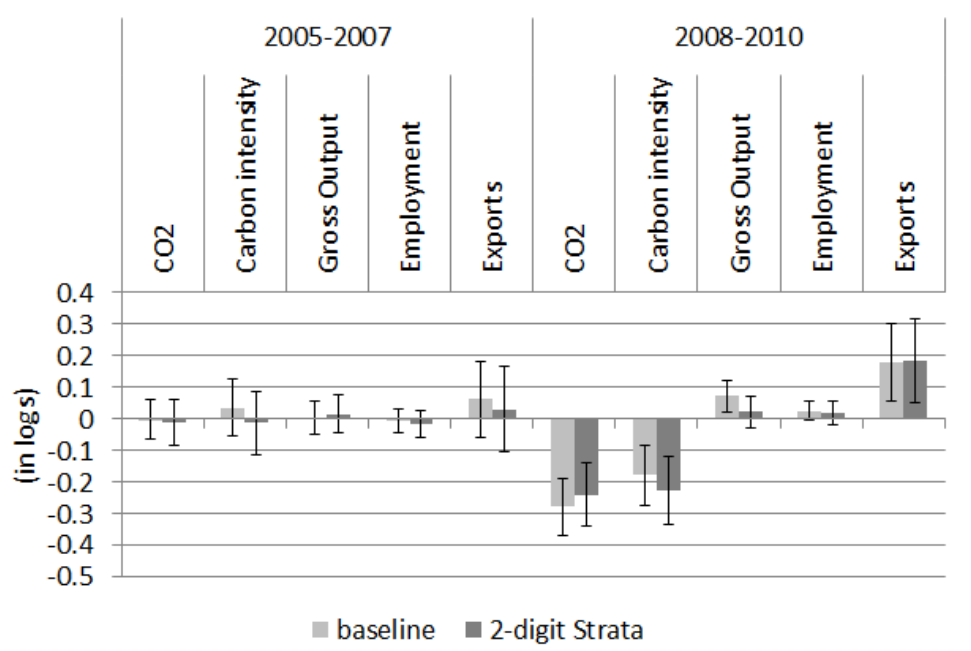

Notes: Error bars represent the $95 \%$ confidence interval. Source: Research Data Centres of the Federal Statistical Office and the Statistical Offices of the Länder (2012): AFiD-Panel Industriebetriebe, 19982010, own calculations.

not reject at the 5 percent level.

Next, we investigate how robust the estimated ATTs are to directly controlling for pre-treatment trends. To this end, we re-estimate the ATTs after matching treated and control firms based on pre-treatment changes (not levels) in the respective outcome variable. Figure 1 shows three sets of alternative ATTs - obtained in the preferred NN(1:1) specification - next to the baseline specification which matches on the outcome variables in levels. The first alternative specification does not match on lagged outcome variables at all, the second one matches on the 2002-2003 change in the outcome variable, and the last one matches on the average change in the outcome variable between the years 2000 and 2003. The resulting point estimates and confidence bands for carbon emissions and intensity are very close to those obtained in the baseline specification. The point estimates of the impact on exports in phase II remain positive, but are no longer statistically significant under the alternative matching strategies. The impact on gross output remains positive and statistically significant except for the case where no pre-treatment output variable is included in the matching algorithm.

As a further check of unconfoundedness, we re-estimate all ATTs af- 
ter imposing exact matching on firms' two-digit sector. This addresses the worry that differential post-treatment shocks across sectors could be confounding the treatment estimates. As shown in Figure 2, the results are very similar to the baseline specification, the only qualitative difference being that the estimate for gross output, though still positive, is not statistically significant in phase II. Recall that the baseline specification imposes exact matching only within two strata (process-regulated sectors vs. all other sectors) and includes two-digit sector dummies in the propensity score estimation. Defining strata at the two-digit sector level rules out matching of, e.g., a treated steel plant with an untreated paper mill, even if both are alike in terms of emissions, gross output, number of employees and the average wage. Instead, the control firm is taken from within the iron and steel sector, even though its characteristics - size, in particular - might differ more than those of the control firm. The robustness of the results to these choices suggests that the trade-off is small $[2$

\section{Stable Unit Treatment Value Assumption (SUTVA)}

As we have noted above, the EU ETS likely affects the entire economy indirectly though rising electricity prices. We seek to identify the effect the policy had on firms over and above this indirect effect. Doing so requires us to rule out the possibility that the direct treatment impact "spills over" from treated to untreated firms. In the program evaluation literature, this assumption is referred to as the Stable Unit Treatment Value Assumption (SUTVA). An immediate concern in this regard arises with spillovers between treated and untreated plants within the firm. We circumvent this problem by conducting the analysis at the firm level, which internalizes such spillovers. ${ }^{23}$ Nonetheless, if firms used to construct the counterfactual are affected by the treatment, their post-treatment outcomes, and thus the estimated treatment effect as well, will be biased. While the SUTVA is

\footnotetext{
${ }^{22}$ Fowlie, Holland and Mansur (2012) combine stratification by industry with nearestneighbor matching on a single covariate. We explore this using 2-digit sector and carbon emissions per employee as the matching covariates, as in Wagner et al. (2013). The results, reported in Table C.4 of the appendix, are qualitatively similar to the baseline specification, although the coefficient estimates are somewhat larger in magnitude.

${ }^{23}$ That is, we focus on the outcome that results after treated firms re-optimize production decisions across plants.
} 
Figure 3: NN (1:1) estimates with matching in non-contiguous states

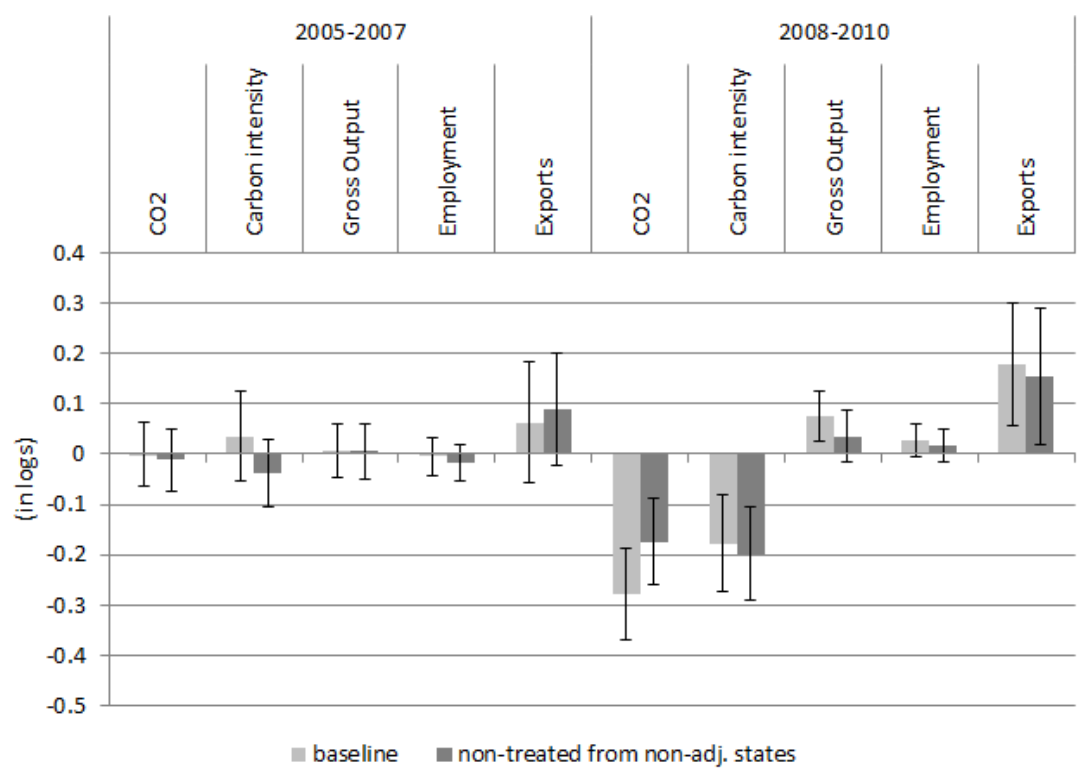

Notes: Error bars represent the $95 \%$ confidence interval. Source: Research Data Centres of the Federal Statistical Office and the Statistical Offices of the Länder (2012): AFiD-Panel Industriebetriebe, 19982010, own calculations.

untestable, Fowlie, Holland and Mansur 2012 ) propose to generate testable hypotheses of how violations of SUTVA would manifest. For example, one such hypothesis would be that the EU ETS caused emissions to shift from treated firms to nearby untreated firms. If this was the case then we would obtain larger treatment effects than when using only untreated firms not affected by those spillovers to construct the counterfactual outcomes. Under the assumption that spillovers are local, we can test this by excluding all control firms that are in the same state as the treated firm or in one adjacent to it. Figure 3 shows that this leads to small - and mostly insignificant - changes in point estimates. The point estimate for $\mathrm{CO}_{2}$ emissions drops in magnitude but remains statistically significant, whereas the treatment effect for gross output becomes statistically insignificant.

\section{Stable covariates}

To avoid matching on endogenous covariates, we estimate the propensity score using covariates from 2003, the year in which the EU Trading Directive was passed. Hence, five years lie between the matching year and 
Figure 4: NN (1:1) estimates with matching in different periods

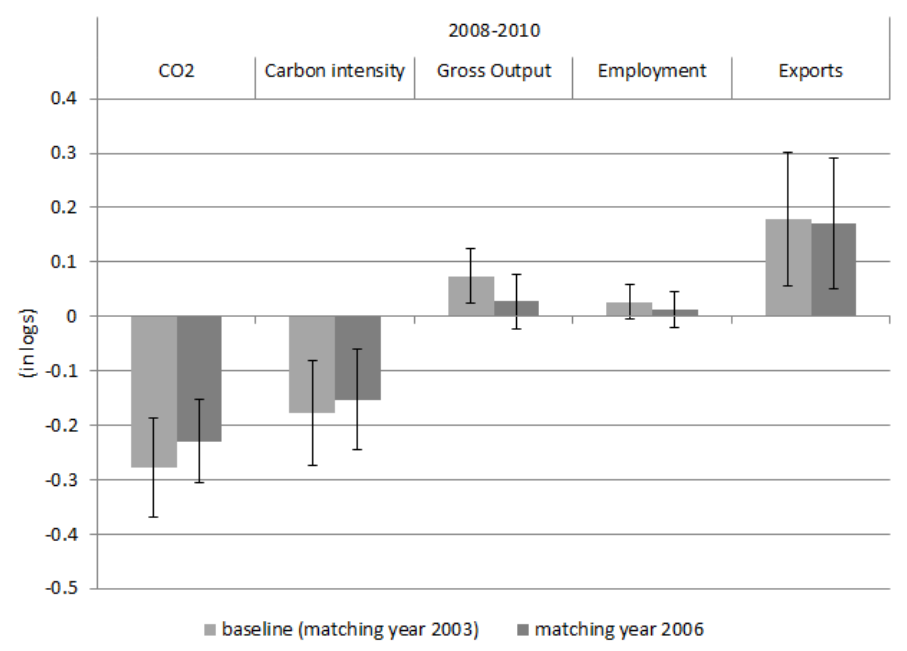

Notes: Error bars represent the $95 \%$ confidence interval. Source: Research Data Centres of the Federal Statistical Office and the Statistical Offices of the Länder (2012): AFiD-Panel Industriebetriebe, 19982010, own calculations.

the beginning of phase II. It is possible that the relevant counterfactual for the treated firms change in this relatively long time period, making the control group unrepresentative when phase II starts. We investigate this by re-estimating the ATTs for the second period after matching the treated and control firms on propensity scores estimated on data from 2006 . While 2006 covariates are not exogenous, the bias should be small given that we do not find large, let alone significant, effects of the treatment in phase I. At the same time, the sensitivity of the ATTs toward change between the two matching years gives us an intuition about whether the counterfactual has changed over time. Figure 4 compares the two sets of treatment effects. Similarly to previous robustness checks, the ATT for gross output becomes insignificant, casting another shred of doubt on the robustness of the positive ATT estimated for gross output. The other results remain qualitatively unchanged. Quantitatively, the point estimate on the emissions reduction drops by one standard deviation, from -0.28 to -0.23 , and the one on carbon intensity from -0.18 to -0.15 (three fifths of a standard deviation). 
Table 5: Pre-treatment Effects for the 2000-2004 period

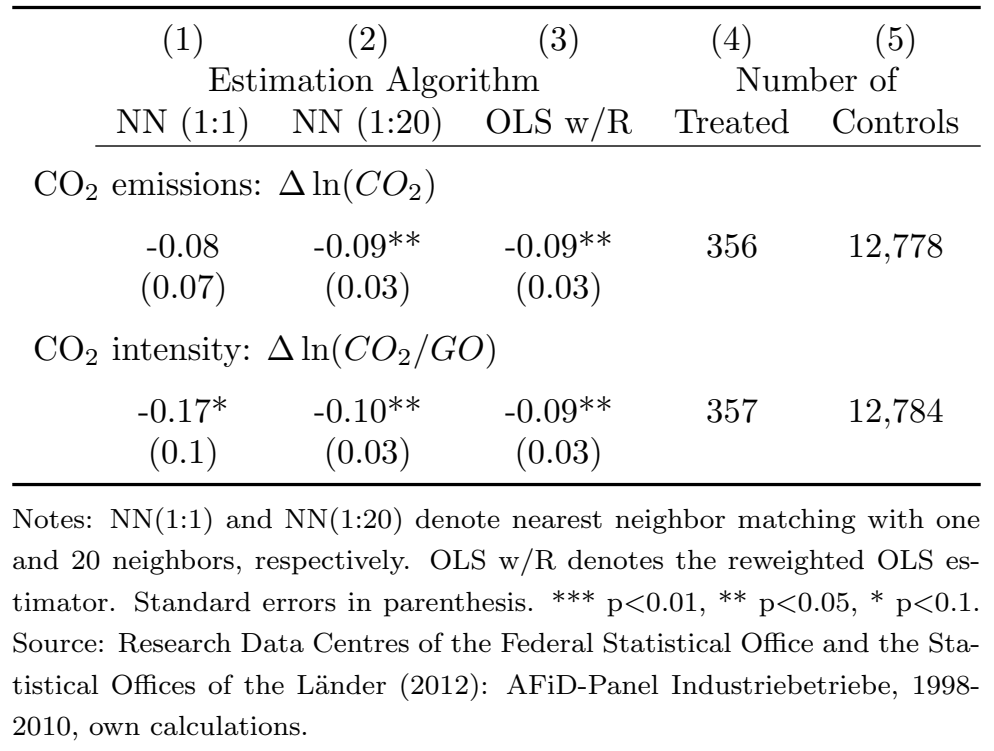

\section{Pre-treatment dynamics}

The EU ETS directive was finalized and announced in October 2003. If the announcement of emissions trading affected firm behavior even before its implementation in 2005, then 2004 would not be the appropriate base year for before-and-after comparisons. In fact, the ATT estimates reported above would not capture the full treatment effect, and the consistency of the matching approach would be impaired as firm characteristics in the year 2003 were no longer exogenous to treatment status. These possible concerns motivate taking a closer look at pre-treatment dynamics.

One can think of two potential causes for a pre-treatment impact - or "announcement effect" - of the EU ETS. On the one hand, firms may have had an incentive to strategically adjust their pre-treatment emissions. That is, they could have switched technologies to steer clear of the thresholds that govern participation, or they could have spurred emissions in order to receive more grandfathered permits in future trading phases. ${ }^{24}$ On the other hand, firms may have taken early action, e.g., by investing in projects that became profitable once the expected payoff from excess emission allowances was taken into account.

\footnotetext{
${ }^{24}$ The base period for the allocation of free permits for phase I was 2000 to 2002 for existing installations. Free permit allocation in phase II was based on emissions during the period 2000-2005.
} 
We estimate the announcement effect using a placebo treatment for the pre-treatment difference in outcomes between 2000 and 2004, after matching treated and control firms using covariates from 1999. While we find no statistically significant treatment effect on employment, gross output and exports, the point estimates for carbon emissions and carbon intensity are negative and statistically significant at the 5 percent level in some specifications, see Table $5^{25}$ If we interpret this to mean that the announcement of the EU ETS decreased emissions, then matching on 2003 emissions in the main specification compares treated firms with controls that are too clean, and would bias the estimated impact on emissions towards zero. However, when we estimate the ATT after matching on 1999 covariates, the impact estimate for carbon emissions hardly changes (the results are reported in Table C.3 in the appendix). If anything, the point estimates are smaller in magnitude, not larger. While there are some differences in magnitude and significance levels for the other outcome variables, there is no logical connection to an announcement effect. These differences are more likely due to the different conditioning strategy and the smaller sample.

\section{The great recession}

Trading phase II coincides with the onset of the deepest economic downturn in recent history, triggered by the financial crisis in September 2008. While the recession struck more mildly in Germany than in most other EU countries, its effects and subsequent recovery are clearly appreciable in the trajectory of real gross output, plotted in panel (d) of Figure C.1 in the appendix. Clearly, this event poses an additional challenge to our identification strategy because, even if counterfactual trends are parallel in "normal" economic conditions, they might not be in a major economic slump. Again, this issue cannot be tested, so we try to assess it in more indirect ways.

A visual inspection of the trends by treatment status suggests that gross output evolved in a parallel fashion even during the recession. To assess this more rigorously, we use ATT estimates to test for differences in real gross output growth between 2007 (pre-crisis) and 2010. Matching

\footnotetext{
${ }^{25}$ The results for gross output and employment are reported in Appendix Table C.2.
} 
firms based on characteristics for the year 2006 ensures that a possible confounding impact of the EU ETS is limited to later years. This exercise yields small and statistically insignificant point estimates for gross output and employment, as shown in Figure $4{ }^{26}$ For there to be a differential effect of the recession, it must be the case that the impacts of the recession and of the EU ETS cancel out.

Finally, we look at macroeconomic fluctuations that occurred when treatment was imminent, such as the economic fallout of the $9 / 11$ terrorist attacks and the dotcom recession, for evidence of a differential effect of recessions on the treatment group. We implement this by estimating placebo ATTs for employment and gross output separately for the treatment periods 2001-2002 and 2001-2004, after matching on 1999 covariates. The results are reported in Table C.2 of the appendix and show no statistically significant differences across treatment groups. While this is reassuring, it is evident that the magnitude of these downturns was much smaller than the 2008/09 recession.

Overall, we conclude that our findings for $\mathrm{CO}_{2}$ emissions, carbon intensity and employment are robust to a host changes to the specification and in the identifying assumptions. While the statistical significance of the positive impact for gross output and exports is not robust to these changes, in no case did they give rise to a negative and significant impact estimate.

\section{How did treated firms reduce carbon emis- sions?}

A robust finding established in the previous section is that the EU ETS caused firms to substantially cut back on $\mathrm{CO}_{2}$ emissions in phase II. Further, this cutback was achieved through a reduction in the carbon intensity rather than the scale of production. In this section we draw on additional data from various sources to shed more light on how treated firms reduced the carbon footprint of production. From a conceptual point of view, firms can achieve this by reducing the carbon intensity for a given level of en-

\footnotetext{
${ }^{26}$ The point estimates are 0.03 for gross output and 0.01 for employment. None of them is statistically significant at the 5 percent level in any of the three specifications.
} 
ergy consumption - for example by switching from high-carbon fuels to low-carbon fuels - or by using energy more efficiently for a given energy mix.

\subsection{Fuel switching}

We look for evidence of fuel switching by estimating the causal impact of the EU ETS separately for the consumption of electricity, primary energy as well as for the most common non-electricity fuels, natural gas and petroleum products. We start by looking at the absolute response, summarized in Table 6. Panel A shows that ATT estimates for electricity consumption are between -0.03 and -0.04 in phase II, but only the OLS reweighting estimate is also statistically significant. In contrast, the estimated ATTs for non-electricity fuels, reported in Panel B, are highly statistically significant, with an increase of between 0.11 and $0.16 \log$ points in phase I and a subsequent decrease by 0.81 to 0.87 log points in phase II. As Panels $\mathrm{C}$ and $\mathrm{D}$ show, this decrease is explained by the strong reductions in both natural gas and oil consumption, with point estimates between -0.21 to -0.33 for the former and between -0.45 and -0.56 for the latter. Moreover, the number of firms consuming natural gas and petroleum products falls by a larger proportion among treated than among untreated firms, as is evident from the last two columns. The point estimates for phase I suggest that some firms engaged in substitution of natural gas for oil, but this effect is not statistically significant in our preferred specification, and - as we already know - did not result in a significant reduction of overall carbon emissions.

Table 7 summarizes the impact of the EU ETS on the fuel shares in overall energy consumption. These results confirm the relative increase of electricity in the fuel mix by 0.26 to 0.28 in phase II, due to the drastic reduction of non-electricity fuels. Panels $\mathrm{C}$ and $\mathrm{D}$ lend additional support to the conjecture that EU ETS firms substituted to low-carbon fuels like natural gas in phase I, as suggested by the increased share of natural gas and the reduced petroleum share. The mostly insignificant point estimates for these fuel shares in phase II corroborate the previous finding that the strong reductions in non-electricity fuels are not counterveiled by increases 
in electricity use.

Overall, these findings suggest that treated firms pursued different strategies to cope with carbon pricing in the two trading phases. While treated firms first switched from high- to low-carbon content among non-electricity fuels, they drastically reduced their use of fossil fuels in phase II. It appears that carbon pricing in phase II increased the cost of generating heat or electricity on site beyond economically viable levels for the average treated firm. Less heat generation on site could mean that treated firms were making more efficient use of process heat, or that they shut down or throttled their on-site power plants. Given that we find no significant impact on electricity consumption, firms that reduced electricity generation on site did so in favor of additional procurement from the grid, thereby transferring the obligation to surrender emission certificates to the electricity provider ${ }^{27}$

\subsection{Technology upgrades and other emissions reduc- ing measures}

To the extent that the substantial reduction in carbon emissions during phase II of the EU ETS cannot be attributed to the substitution toward fuels with a lower emissions intensity, it is likely the result of increased energy conservation efforts. For instance, the adoption of more efficient technologies tends to reduce energy use. We test for this possibility by estimating the impact of the EU ETS on investment and gross investment. The results, which are reported in Table C.6 in the appendix, show that the EU ETS had no statistically significant impact on investment in either of the two trading phases.

While this exhausts the range of abatement options we can test for using AFiD data, it is far from exhausting firms' options to abate $\mathrm{CO}_{2}$ emissions. To shed light on other ways of reducing $\mathrm{CO}_{2}$ emissions, we resort to qualitative data from a broad-based survey of managers at medium-sized European manufacturing firms. The data were collected by Martin et al. (2013a) using a bias-reducing, "double-blind" telephone interview method developed by Bloom and van Reenen (2007). Participating firms were drawn at random

\footnotetext{
${ }^{27}$ Remember that we only estimate the direct effect of the EU ETS on firms, over and above any indirect effect induced via the electricity sector.
} 
Table 6: Impact on fuel use

\begin{tabular}{|c|c|c|c|c|c|}
\hline & (1) & $(2)$ & $(3)$ & $(4)$ & $(5)$ \\
\hline & \multicolumn{3}{|c|}{ Estimation Algorithm } & \multicolumn{2}{|c|}{ Number of } \\
\hline & NN $(1: 1)$ & NN $(1: 20)$ & OLS w/R & Treated & Controls \\
\hline \multicolumn{6}{|c|}{ A. Electricity consumption: $\Delta \ln (E L E C)$} \\
\hline Phase I & $\begin{array}{c}0.01 \\
(0.03)\end{array}$ & $\begin{array}{c}0.03 \\
(0.02)\end{array}$ & $\begin{array}{c}0.02 \\
(0.03)\end{array}$ & 453 & 27,699 \\
\hline Phase II & $\begin{array}{c}-0.04 \\
(0.03)\end{array}$ & $\begin{array}{c}-0.03 \\
(0.02) \\
\end{array}$ & $\begin{array}{c}-0.04^{* *} \\
(0.02)\end{array}$ & 428 & 23,867 \\
\hline
\end{tabular}

B. Consumption of all non-electricity fuels: $\Delta \ln (E P R I M A R Y)$

\begin{tabular}{cccccc} 
Phase I & $0.16^{* * *}$ & $0.13^{* * *}$ & $0.11^{* * *}$ & 435 & 24,601 \\
& $(0.05)$ & $(0.04)$ & $(0.03)$ & & \\
Phase II & $-0.81^{* *}$ & $-0.83^{* *}$ & $-0.87^{* *}$ & 376 & 21,331 \\
& $(0.15)$ & $(0.11)$ & $(0.1)$ & & \\
\hline
\end{tabular}

C. Consumption of natural gas: $\Delta \ln (G A S)$

\begin{tabular}{cccccc} 
Phase I & 0.01 & $0.10^{* *}$ & $0.11^{* *}$ & 412 & 16,817 \\
& $(0.07)$ & $(0.04)$ & $(0.04)$ & & \\
Phase II & $-0.21^{* *}$ & $-0.32^{* *}$ & $-0.33^{* *}$ & 217 & 10,506 \\
& $(0.11)$ & $(0.08)$ & $(0.07)$ & & \\
\hline
\end{tabular}

D. Consumption of petroleum products: $\Delta \ln (O I L)$

$\begin{array}{cccccc}\text { Phase I } & -0.05 & -0.02 & -0.15^{* *} & 232 & 8,857 \\ & (0.12) & (0.08) & (0.07) & & \\ \text { Phase II } & -0.56^{* *} & -0.45^{* *} & -0.48^{* *} & 163 & 7,815 \\ & (0.17) & (0.11) & (0.13) & & \end{array}$

Notes: $\mathrm{NN}(1: 1)$ and $\mathrm{NN}(1: 20)$ denote nearest neighbor matching with one and 20 neighbors, respectively. OLS w/R denotes the reweighted OLS estimator. Standard errors in parenthesis. ${ }^{* * *} \mathrm{p}<0.01,{ }^{* *} \mathrm{p}<0.05,{ }^{*} \mathrm{p}<0.1$. Source: Research Data Centres of the Federal Statistical Office and the Statistical Offices of the Länder (2012): AFiD-Panel Industriebetriebe, 1998-2010, own calculations. 
Table 7: Impact on fuel shares in total energy use

\begin{tabular}{|c|c|c|c|c|c|}
\hline & (1) & $(2)$ & $(3)$ & $(4)$ & $(5)$ \\
\hline & \multicolumn{3}{|c|}{ Estimation Algorithm } & \multicolumn{2}{|c|}{ Number of } \\
\hline & NN $(1: 1)$ & NN $(1: 20)$ & OLS w/R & Treated & Controls \\
\hline \multicolumn{6}{|c|}{ A. Electricity share: $\Delta \ln (E L E C / E N E R G Y)$} \\
\hline Phase I & $\begin{array}{l}-0.01 \\
(0.03)\end{array}$ & $\begin{array}{c}-0.02 \\
(0.02)\end{array}$ & $\begin{array}{l}-0.04^{*} \\
(0.02)\end{array}$ & 441 & 27,716 \\
\hline Phase II & $\begin{array}{c}0.26^{* * *} \\
(0.06)\end{array}$ & $\begin{array}{c}0.27^{* * *} \\
(0.04)\end{array}$ & $\begin{array}{c}0.28 * * * \\
(0.03)\end{array}$ & 378 & 23,863 \\
\hline
\end{tabular}

B. Share of non-electricity fuels: $\Delta \ln (E P R I M A R Y / E N E R G Y)$

$\begin{array}{cccccc}\text { Phase I } & 0.07^{* *} & 0.08^{* * *} & 0.08^{* * *} & 443 & 24,586 \\ & (0.03) & (0.02) & (0.02) & & \\ \text { Phase II } & -0.40^{* *} & -0.42^{* *} & -0.47^{* *} & 380 & 21,320 \\ & (0.10) & (0.08) & (0.07) & & \\ \end{array}$

C. Share of natural gas: $\Delta \ln (G A S / E N E R G Y)$

\begin{tabular}{cccccc} 
Phase I & $0.13^{* * *}$ & $0.12^{* * *}$ & $0.11^{* * *}$ & 414 & 16,810 \\
& $(0.05)$ & $(0.03)$ & $(0.04)$ & & \\
Phase II & 0.02 & $-0.14^{* *}$ & $-0.19^{* *}$ & 220 & 10,509 \\
& $(0.09)$ & $(0.06)$ & $(0.05)$ & & \\
\hline
\end{tabular}

D. Share of petroleum products: $\triangle \ln (O I L / E N E R G Y)$

\begin{tabular}{lccccc} 
Phase I & $-0.18^{*}$ & -0.08 & $-0.21^{* *}$ & 230 & 9,156 \\
& $(0.10)$ & $(0.08)$ & $(0.07)$ & & \\
Phase II & 0.06 & 0.18 & 0.12 & 167 & 7,842 \\
& $(0.16)$ & $(0.12)$ & $(0.15)$ & & \\
\hline
\end{tabular}

Note: $\mathrm{NN}(1: 1)$ and $\mathrm{NN}(1: 20)$ denote nearest neighbor matching with one and 20 neighbors, respectively. OLS w/R denotes the reweighted OLS estimator. Standard errors in parenthesis. ${ }^{* * *} \mathrm{p}<0.01,{ }^{*} \mathrm{p}<0.05,{ }^{*} \mathrm{p}<0.1$. Source: Research Data Centres of the Federal Statistical Office and the Statistical Offices of the Länder (2012): AFiDPanel Industriebetriebe, 1998-2010, own calculations. 
from all mid-sized firms contained in a large commercial database (Bureau van Dijk, 1999-2008). We use data on 138 German firms that were interviewed between late August and October 2009. Due to oversampling of EU ETS firms, 95 of the firms participate in the EU ETS. Appendix B describes aspects of the data collection in more detail.

We focus on interview responses pertaining to measures that were implemented at the production site in order to reduce carbon dioxide emissions ${ }^{28}$ Table 8 summarizes these measures. The mean adoption rates reported in column 1 highlight the role of optimization processes that affect the use of machinery or heating and cooling for emissions abatement. Improving the production process or upgrading machinery is the most common such measure, with an adoption rate of 63 percent, followed by optimized use of process heat (38 percent) and optimization of the exhaust air system or district heating system (28 percent). A second tier of measures reduces the carbon content of generation on site via combined heat and power (CHP) generation (13 percent) or exploitation of renewable energy sources (14 percent). In addition, numerous measures target the reduction of energy use through efficiency improvements, e.g., of buildings (18 percent), the compressed air system (15 percent) or lighting (12 percent), through the introduction or upgrading of an energy management system (15 percent), via staff training (12 percent) and external energy audits ( 8 percent). Only 8 percent of respondents conduct process innovation that leads to emissions reductions.

We investigate how these measures are associated with participation in the EU ETS. Column 2 reports the coefficient obtained in probit regressions of adoption on the treatment dummy, conditional on employment size and controls for interview noise. This reveals that ETS firms are significantly more likely to make better use of process heat and to optimize processes specific to their industry. In contrast, ETS participation is negatively associated with modernizing the lighting system and energy efficient site extension/insulation/building management.

Furthermore, column 3 summarizes the adoption rates for the one mea-

\footnotetext{
${ }^{28}$ Managers were asked "Can you tell me what measures you have adopted in order to reduce GHG emissions (or energy consumption) on this site? Have you bought any new equipment, or have you changed the way you produce?"
} 
Table 8: Adoption of emissions reducing measures

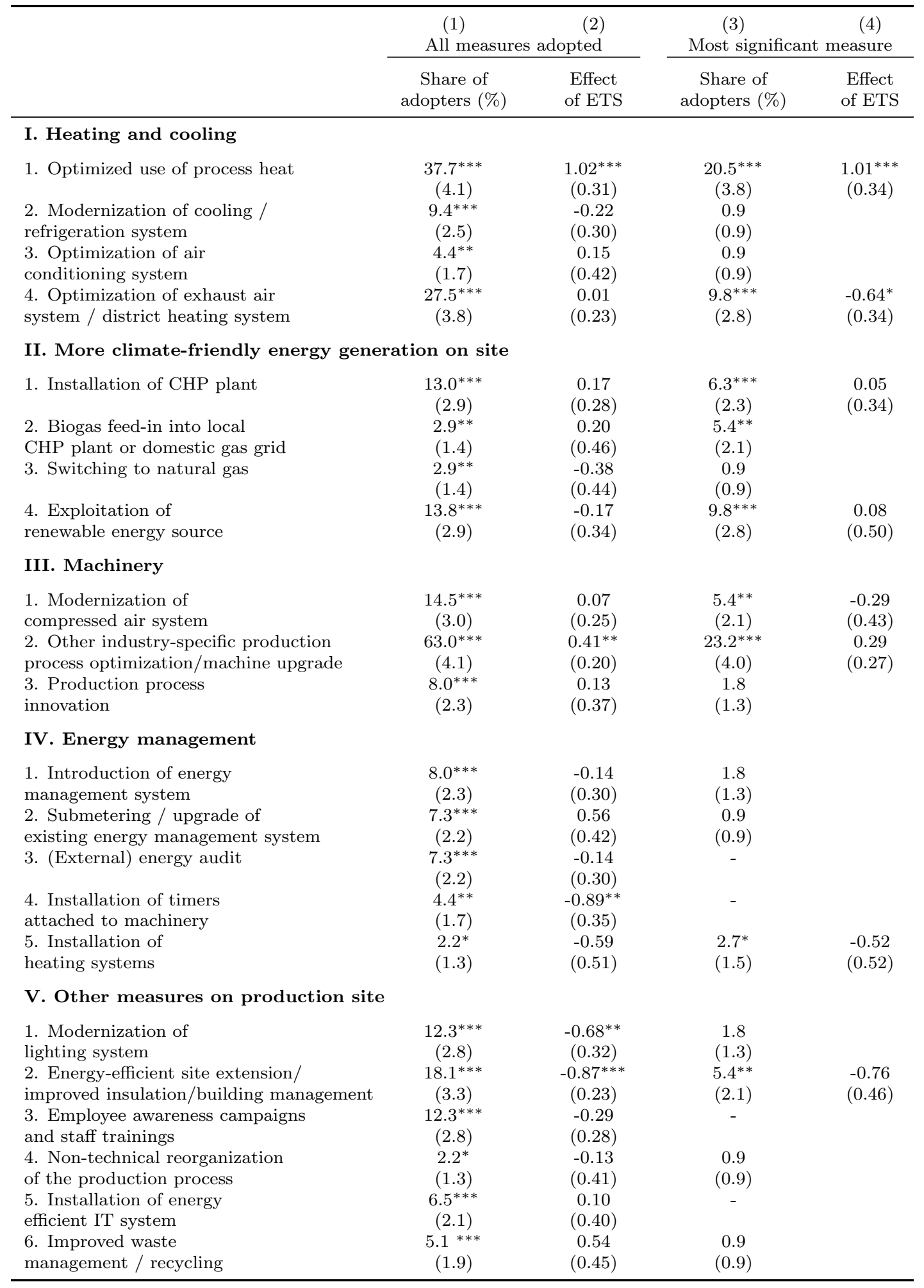

Notes: Based on telephone interviews with managers of 138 German manufacturing firms, 95 of which were EU ETS participants in 2009. Columns (1) and (3) report the mean and standard deviation (in parentheses) of the adoption rate for a given measure. Columns (2) and (4) report the coefficient on EU ETS participation in a probit regression of adoption, controlling for employment size, interviewer fixed effects, and respondent characteristics. Standard errors in parentheses are clustered at the 3-digit sector level. 
sure that achieved the largest reduction in carbon emissions.29 This confirms once again the importance of optimizing industry-specific processes and use of process heat for reducing carbon emissions. In fact, the latter is the only measure for which we obtain a positive association with ETS participation that is significant at the 5 percent level (reported in column 4).

Needless to say, these correlations do not necessarily represent causal relationships. Together with the causal impact estimates from the previous subsection, however, they provide a consistent answer to the question posed in the title of this section. To abate $\mathrm{CO}_{2}$ emissions, treated firms reduced heat rather than electricity consumption through the optimized use of process heat, particularly improved recovery of waste heat.

\section{Conclusion}

In this paper we have presented new econometric evidence on the causal impact for the EU ETS on $\mathrm{CO}_{2}$ emissions and on economic performance in the manufacturing sector. Drawing on high-quality microdata for German manufacturing firms, our analysis yields two principal findings.

First, we establish that the EU ETS caused treated firms to reduce their $\mathrm{CO}_{2}$ emissions by one-fifth relative to non-treated firms, and we go to considerable lengths to explain how firms managed to abate their carbon emissions. While it is not difficult to think of reasons why the abatement occurred entirely in the second trading phase, we leave it as a task for future research to disentangle competing explanations 30

Our second main result is the failure to reject the hypothesis that the EU ETS had no negative effect on gross output, employment or exports over the sample period. This contrasts with claims by industry associations that a regional carbon trading scheme leads to drastic job losses. It also

\footnotetext{
${ }^{29}$ Managers were asked: "Which one of these measures achieved the largest carbon saving?", referring to the measures named in response to the previous question.

${ }^{30}$ For example, the marginal incentive to curb emissions was very low during the second half of phase I because the overall cap was revealed to be not binding, and because banking of permits for use in later trading phases was prohibited. The marked knock-on effect of abatement in phase II is consistent with this explanation, inasmuch as overall emissions target in phase II was tighter and unlimited banking of permits for future use provided stronger intertemporal abatement incentives.
} 
casts doubt on the legitimacy of the generous compensation that European manufacturing industries receive from the EU Commission for presumably adverse competitiveness effects of the EU ETS (Martin et al., 2013a b). As most of German exports go to other EU countries where industry is also subject to the EU ETS, an analysis of exports to non-EU countries should provide more direct evidence on the issue of international competitiveness. Because the AFiD dataset does not provide the precise destination of exports, this is left as a topic for future research.

Our study has focused on Germany, the largest economy in the EU ETS, its largest emitter, and a leading exporter of manufactured goods in the world. All of these aspects make Germany a natural starting place for a comprehensive policy evaluation of the causal impact of the EU ETS, but future research will not stop here. Collecting and analyzing suitable microdata across a large set of member states is necessary to obtain a complete picture of the effects of this landmark policy.

\section{References}

Abrell, Jan, Anta Ndoye, and Georg Zachmann. 2011. "Assessing the Impact of the EU ETS Using Firm Level Data." Bruegel Working Paper 2011-08.

Anderson, B., and C. Di Maria. 2011. "Abatement and Allocation in the Pilot Phase of the EU ETS." Environmental and Resource Economics, 1-21.

Anger, Niels, and Ulrich Oberndorfer. 2008. "Firm Performance and Employment in the EU Emissions Trading Scheme: An Empirical Assessment for Germany." Energy Policy, 36(1): 12-22.

Bloom, N., and J. van Reenen. 2007. "Measuring and Explaining Management Practices across Firms and Countries." Quarterly Journal of Economics, CXXII(4): 1351-1406.

Bloom, Nicholas, and John van Reenen. 2010. "New Approaches to Surveying Organizations." American Economic Review, 100(2): 105-09.

Bureau van Dijk. 1999-2008. "ORBIS data base." http://www.bvdinfo.com. (accessed July, 2009). 
Bushnell, James B., Howard Chong, and Erin T. Mansur. 2013. "Profiting from Regulation: Evidence from the European Carbon Market." American Economic Journal: Economic Policy, 5(4): 78-106.

Busso, Matias, John DiNardo, and Justin McCrary. 2013. "New Evidence on the Finite Sample Properties of Propensity Score Reweighting and Matching Estimators." Review of Economics and Statistics, forthcoming.

Calel, Raphael, and Antoine Dechezleprêtre. 2012. "Environmental Policy and Directed Technological Change: Evidence from the European Carbon Market." London School of Economics CEP Discussion Paper 1141.

Chan, Hei S., Shanjun Li, and Fan Zhang. 2013. "Firm Competitiveness and the European Union Emissions Trading Scheme." Energy Policy, 63: 1056-1064.

Commins, Nicola, Seán Lyons, Marc Schiffbauer, and Richard S.J. Tol. 2011. "Climate Policy and Corporate Behavior." The Energy Journal, 32(4): 51-68.

Demailly, Damien, and Philippe Quirion. 2006. "CO2 Abatement, Competitiveness and Leakage in the European Cement Industry under the EU ETS: Grandfathering versus Output-based Allocation." Climate Policy, 6(1): 93-113.

Demailly, Damien, and Philippe Quirion. 2008. "European Emission Trading Scheme and Competitiveness: A Case Study on the Iron and Steel Industry." Energy Economics, 30(4): 2009-2027.

Ellerman, A. D., and S. M. Feilhauer. 2008. "A Top-down and Bottom-up Look at Emissions Abatement in Germany in Response to the EU ETS." Working Paper, MIT Center for Energy and Environmental Policy Research, n2008.017, http://hdl.handle.net/1721.1/45661.

Ellerman, A. Denny, and Barbara K. Buchner. 2007. "The European Union Emissions Trading Scheme: Origins, Allocation, and Early Results." Review of Environmental Economics and Policy, 1(1): 66-87.

Ellerman, A. Denny, and Barbara K. Buchner. 2008. "OverAllocation or Abatement? A Preliminary Analysis of the EU ETS Based on the 2005/06 Emissions Data." Environmental and Resource Economics, 41(2): 267-287. 
Ellerman, A. Denny, Claudio Marcantonini, and Aleksandar Zaklan. 2014. "The EU ETS: Eight Years and Counting." Robert Schuman Centre for Advanced Studies Research Paper 2014/04.

Ellerman, A. Denny, Frank J. Convery, and Christian de Perthuis. 2010. Pricing Carbon: The European Union Emissions Trading Scheme. . 1 ed., Cambridge University Press.

Ellerman, A. Denny, Paul L. Joskow, Richard Schmalensee, JuanPablo Montero, and Elizabeth M. Bailey. 2000. Markets for Clean Air: The U.S. Acid Rain Program. Cambridge University Press.

EU Commission. 2005-2010. "European Union Transaction Log (EUTL)." http://ec.europa.eu/environment/ets. (accessed June, 2011).

European Commission. 2009. "Directive 2009/29/EC of the European Union and of the council of 23 April 2009 amending directive 2003/87/EC so as to improve and extend the greenhouse gas emission allowance trading scheme of the community."

Fabra, Natalia, and Mar Reguant. 2014. "Pass-through of Emissions Costs in Electricity Markets." American Economic Review, forthcoming.

Federal Statistical Office. 2012. "Index der Erzeugerpreise gewerblicher Produkte. Fachserie 17 Reihe 2." https://wwwgenesis.destatis.de/genesis/online. (accessed July 2011).

Fowlie, Meredith, and Jeffrey M. Perloff. 2013. "Distributing Pollution Rights in Cap-and-Trade Programs: Are Outcomes Independent of Allocation?" Review of Economics and Statistics, 95(5): 1640-1652.

Fowlie, Meredith, Stephen P. Holland, and Erin Mansur. 2012. "What Do Emissions Markets Deliver and to Whom? Evidence from Southern California's NOx Trading Program." American Economic Review, 102(2): 965-993.

Heckman, James J., Hidehiko Ichimura, and Petra E. Todd. 1997. "Matching as an Econometric Evaluation Estimator: Evidence from Evaluating a Job Training Programme." The Review of Economic Studies, 64(4): 605-654.

Heckman, James J., Hidehiko Ichimura, and Petra Todd. 1998. "Matching as an Econometric Evaluation Estimator." The Review of Economic Studies, 65(2): 261-294. 
Hirano, Keisuke, and Guido W. Imbens. 2001. "Estimation of Causal Effects using Propensity Score Weighting: An Application to Data on Right Heart Catheterization." Health Services and Outcomes Research Methodology, 2(3-4): 259-278.

Imbens, Guido W. 2004. "Nonparametric Estimation of Average Treatment Effects Under Exogeneity: A Review." The Review of Economics and Statistics, 86(1): 4-29.

Kenber, Mark, Oliver Haugen, and Madeleine Cobb. 2009. "The Effects of EU Climate Legislation on Business Competitiveness: A Survey and Analysis." Climate $\&$ Energy Paper Series, The German Marshall Fund of the United States.

Linn, Joshua. 2010. "The effect of cap-and-trade programs on firms' profits: Evidence from the Nitrogen Oxides Budget Trading Program." Journal of Environmental Economics and Management, 59(1): 1-14.

Lunceford, Jared K, and Marie Davidian. 2004. "Stratification and Weighting Via the Propensity Score in Estimation of Causal Treatment Effects: A Comparative Study." Statistics in Medicine, 23: 2937-2960.

Martin, Ralf, Mirabelle Muûls, and Ulrich J. Wagner. 2013. "The Impact of the EU ETS on Regulated Firms: What is the Evidence After Eight Years?" http://ssrn.com/abstract $=2344376$.

Martin, Ralf, Mirabelle Mû̂ls, Laure B. de Preux, and Ulrich J. Wagner. 2013a. "Industry Compensation Under Relocation Risk: A Firm-Level Analysis of the EU Emissions Trading Scheme." American Economic Review, forthcoming.

Martin, Ralf, Mirabelle Muûls, Laure B. de Preux, and Ulrich J. Wagner. 2013b. "On the Empirical Content of Carbon Leakage Criteria in the EU Emissions Trading Scheme." http://ssrn.com/abstract $=2362820$.

McKinsey, and Ecofys. 2006a. "EU ETS REVIEW Report on International Competitiveness." European Commission Directorate General for Environment, Brussels.

McKinsey, and Ecofys. 2006b. "Review of Emissions Trading Scheme: Survey highlights." European Commission Directorate General for Environment, Brussels.

Petrick, Sebastian, Katrin Rehdanz, and Ulrich J. Wagner. 2011. "Energy Use Patterns in German Industry: Evidence from Plant-level 
Data." Journal of Economics and Statistics (Jahrbuecher fuer Nationaloekonomie und Statistik), 231(3): 379-414.

Point Carbon. 2005-2014. "ICE Last Traded Prices." http://www.pointcarbon.com/news/marketdata/euets/forward/eua/. (accessed February, 2014).

Research Data Centres of the Federal Statistical Office and the Statistical Offices of the Länder. 1995-2010. "AFiD-Panel Industriebetriebe." Research data file. (accessed November, 2012).

Rosenbaum, Paul R., and Donald B. Rubin. 1983. "The Central Role of the Propensity Score in Observational Studies for Causal Effects." Biometrika, 70(1): 41-55.

Sijm, J., K. Neuhoff, and Y. Chen. 2006. " $\mathrm{CO}_{2}$ cost pass-through and windfall profits in the power sector." Climate Policy, 6(1): 49-72.

Veith, Stefan, Jörg R. Werner, and Jochen Zimmermann. 2009. "Capital market response to emission rights returns: Evidence from the European power sector." Energy Economics, 31(4): 605-613.

Wagner, Ulrich J., Mirabelle Muûls, Ralf Martin, and Jonathan Colmer. 2013. "The Causal Effect of the European Union Emissions Trading Scheme: Evidence from French Manufacturing Installations." Unpublished.

Zachmann, G., and C. Von Hirschhausen. 2008. "First evidence of asymmetric cost pass-through of EU emissions allowances: Examining wholesale electricity prices in Germany." Economics Letters, 99(3): 465469 . 


\section{Appendix (For Online Publication)}

\section{A Policy Background}

\section{A.1 Activities and thresholds for ETS eligibility}

European Commission (2009) covers the following activities (cf. Annex I) $:^{1}$

- Energy activities

- Combustion installations with a rated thermal input exceeding 20 MW (except hazardous or municipal waste installations)

- Mineral oil refineries

- Coke ovens

- Production and processing of ferrous metals

- Metal ore (including sulfide ore) roasting or sintering installations

- Installations for the production of pig iron or steel (primary or secondary fusion) including continuous casting, with a capacity exceeding 2.5 tons per hour

- Mineral industry

- Installations for the production of cement clinker in rotary kilns with a production capacity exceeding 500 tons per day or lime in rotary kilns with a production capacity exceeding 50 tons per day or in other furnaces with a production capacity exceeding 50 tons per day

- Installations for the manufacture of glass including glass fiber with a melting capacity exceeding 20 tons per day

- Installations for the manufacture of ceramic products by firing, in particular roofing tiles, bricks, refractory bricks, tiles, stoneware or porcelain, with a production capacity exceeding 75 tons per day, and/or with a kiln capacity exceeding $4 \mathrm{~m}^{3}$ and with a setting density per kiln exceeding $300 \mathrm{~kg} / \mathrm{m}^{3}$

- Other activities

\footnotetext{
${ }^{1}$ Note that the directive covers more activities, we list those relevant for our period of observation.
} 
- Industrial plants for the production of (a) pulp from timber or other fibrous materials

- Industrial plants for the production of (b) paper and board with a production capacity exceeding 20 tons per day 


\section{B Background on manager interviews}

Interviews were carried out by graduate and postgraduate students after they had been trained. The interviewers were paid according to the number of interviews conducted, encouraging them to conduct more interviews and discouraging any firm background research, thus preserving the doubleblind nature of the survey. Interviewers made "cold calls" to production facilities (not head offices), gave their name and affiliation and then asked to be put through to the production or environmental manager. In the case of EU ETS firms, interviewers requested to speak to the person responsible for the EU ETS. At this stage, the terms "survey" and "research" were avoided as both are associated with commercial market research and some switchboard operators have instructions to reject such calls. Instead, the interviewers told them that they were doing "a piece of work" on climate change policies and their impact on competitiveness in the business sector and that they would like to have a conversation with the manager best informed.

Once the manager was on the phone, the interviewer asked whether s/he would be willing to have a conversation of approximately 40-45 minutes about these issues. Depending on the manager's willingness and availability to do so, an interview was scheduled. If the manager refused, s/he was asked to provide the interviewer with another knowledgeable contact at the firm who might be willing to comment. Managers who agreed to give an interview were sent an email with a letter in PDF format to confirm the date and time of the interview and to provide background information and assure them of confidentiality. A similar letter was sent to managers who requested additional information before scheduling an interview.

All interviewers worked on computers with an internet connection and used VOIP software to conduct the interviews. They accessed a central interview database via a custom-built, secure web interface which included a scheduling tool and the interview application which displayed the questions along with the scoring grid. The interview screen contained hyperlinks to a manual with background information on each question. Interviewers scored answers during the interview. For all interviews, the scheduling history as well as the exact time and date, duration, identity of interviewer, etc. were recorded. All interviews were conducted in the language of the interviewee's residence.

The interview format follows the design pioneered by Bloom and van Reenen (2007). This approach seeks to minimize cognitive bias by asking open-ended questions and by delegating the task of scoring the answers to the interviewer. In addition, a large sample size and interviewer rotation is exploited to control for possible bias on the part of the interviewers by including interviewer fixed effects in regression analyses. For further 
Table B.1: Interview response rates by country

\begin{tabular}{lcc}
\hline Variable & Germany & All countries \\
\hline Number of firms interviewed & 138 & 761 \\
- of which in EU ETS & 95 & 429 \\
- of which not in EU ETS & 43 & 332 \\
Number of firms contacted & 337 & 1451 \\
Number of firms refused & 199 & 691 \\
Response rate & $41 \%$ & $52 \%$ \\
\hline
\end{tabular}

Table B.2: Firm characteristics by ETS participation status

\begin{tabular}{|c|c|c|c|c|c|c|}
\hline & \multicolumn{3}{|c|}{ ETS Firms } & \multicolumn{3}{|c|}{ non ETS Firms } \\
\hline & Mean & Std. Dev. & Obs. & Mean & Std. Dev. & Obs. \\
\hline \multicolumn{7}{|l|}{ Firm } \\
\hline Age (years) & 47 & 48 & 89 & 49 & 80 & 42 \\
\hline Turnover (EUR million) & $1,028.15$ & $2,319.12$ & 74 & 505.81 & $2,226.71$ & 32 \\
\hline Number of employees & 1,749 & 4,404 & 85 & 609 & 1,477 & 38 \\
\hline EBIT (EUR million) & 35.96 & 139.97 & 65 & 1.82 & 17.06 & 18 \\
\hline Number of shareholders & 3 & 6 & 95 & 2 & 1 & 43 \\
\hline Number of subsidiaries & 11 & 62 & 95 & 2 & 5 & 43 \\
\hline \multicolumn{7}{|c|}{ Firm's Global Ultimate Owner } \\
\hline Turnover (USD million) & 13,844 & 17,470 & 25 & 11,996 & 20,955 & 9 \\
\hline Number of employees & 24,083 & 32,157 & 25 & 49,104 & 73,834 & 8 \\
\hline
\end{tabular}

Notes: Based on 2007 data. None of the respective means for ETS and non ETS firms are significantly different at the $10 \%$ level or better. Source: ORBIS database (Bureau van Dijk), own elaboration.

details, see Bloom and van Reenen (2010).

Table B.1 provides an overview of the number of interviews and the response rates broken down by country and by EU ETS participation status.2 The last line reports the response rate as the fraction of firms that were contacted and with whom an interview took place. Table B.2 reports the further descriptive statistics of the firms surveyed in Germany, taken from the ORBIS data base.

\section{Additional Tables and Figures}

\footnotetext{
${ }^{2}$ All analysts would first conduct interviews in the UK and only then go on to conduct interviews in another country allowing a common reference, hence the larger number of interviews for this country. This allows us to control for interviewer bias as discussed below and also for UK responses to be used as a benchmark.
} 
Figure C.1: Outcome Trends By Treatment Status

(a) $\mathrm{CO}_{2}$ emissions

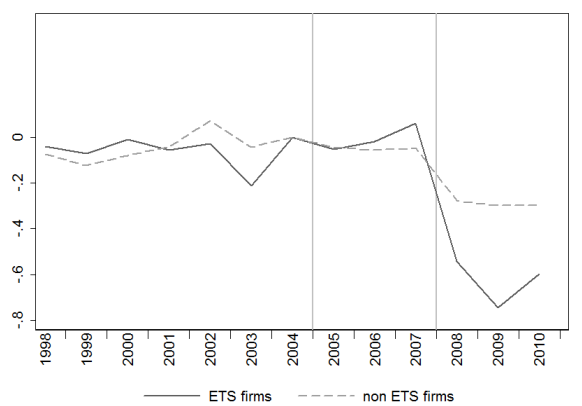

(c) Employment

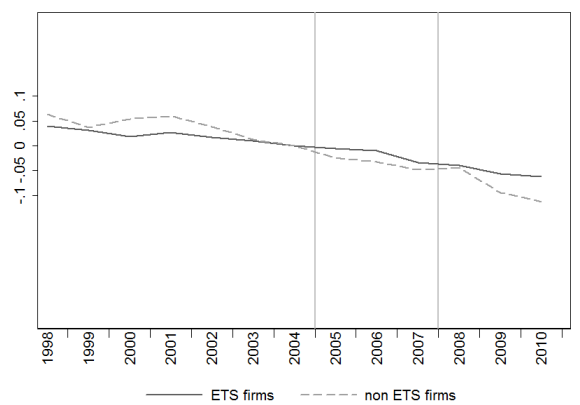

(e) Total exports

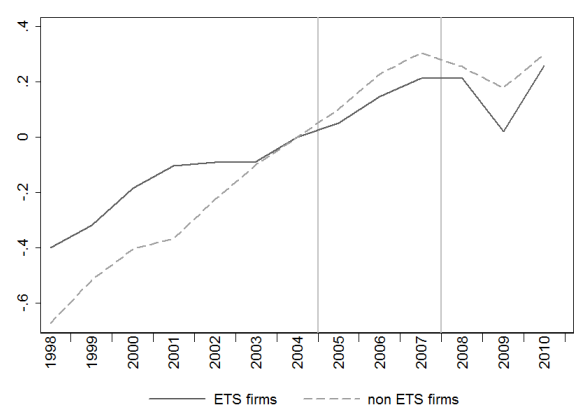

(b) $\mathrm{CO}_{2}$ intensity of gross output

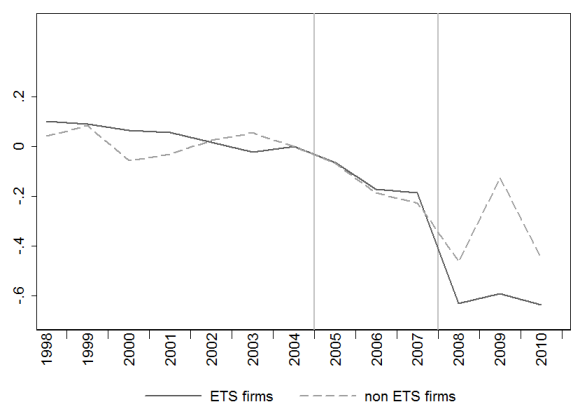

(d) Real gross output

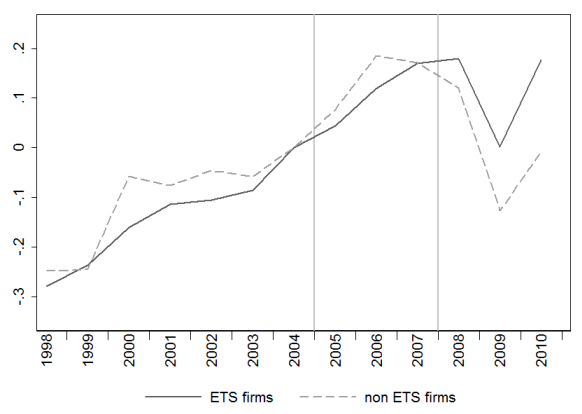

Notes: The figure plots the trends in log outcome variables for treated and non-treated plants. Both series are normalized to with respect to their 2004 values. The sample consists of treated and control firms in our NN(1:1) specification which remain in the sample in all years. Source: Research Data Centres of the Federal Statistical Office and the Statistical Offices of the Länder (2012): AFiD-Panel Industriebetriebe, 1998-2010, own calculations. 
Table C.1: Propensity score estimation by stratum

\begin{tabular}{|c|c|c|c|c|}
\hline & (1) & $(2)$ & $(3)$ & (4) \\
\hline & \multicolumn{2}{|l|}{ Phase I } & \multicolumn{2}{|c|}{ Phase II } \\
\hline & $\begin{array}{l}\text { Process-regulated } \\
\text { sectors }\end{array}$ & $\begin{array}{c}\text { Other } \\
\text { sectors }\end{array}$ & $\begin{array}{l}\text { Process-regulated } \\
\text { sectors }\end{array}$ & $\begin{array}{l}\text { Other } \\
\text { sectors }\end{array}$ \\
\hline \multirow[t]{2}{*}{$\mathrm{CO}_{2}$ emissions } & $43^{* * *}$ & $45^{* * *}$ & $56^{* * *}$ & $48^{* * *}$ \\
\hline & $(5)$ & $(6)$ & (6) & (7) \\
\hline \multirow[t]{2}{*}{ Employees } & 699 & $4567^{* * *}$ & $3058 * * *$ & $3922^{* * *}$ \\
\hline & $(1731)$ & $(891)$ & $(1372)$ & $(559)$ \\
\hline \multirow[t]{2}{*}{ Gross output } & 7.0 & -2.0 & $-6.0^{* *}$ & 0.3 \\
\hline & $(7.0)$ & $(4.0)$ & $(3.0)$ & $(2.0)$ \\
\hline \multirow[t]{2}{*}{ Average wage rate } & $1045^{* * *}$ & $1170^{* * *}$ & $903^{* * *}$ & $1110^{* * *}$ \\
\hline & $(221)$ & $(216)$ & $(249)$ & $(230)$ \\
\hline \multirow[t]{2}{*}{ Export share of output } & $1.94^{* * *}$ & $1.03^{* *}$ & $2.15^{* * *}$ & $1.31^{* *}$ \\
\hline & $(0.52)$ & $(0.48)$ & $(0.57)$ & $(0.52)$ \\
\hline \multirow[t]{2}{*}{$\left(\mathrm{CO}_{2} \text { emissions }\right)^{2}$} & $-0.004^{* * *}$ & $-0.020 * * *$ & $-0.006^{* * *}$ & $-0.010^{* * *}$ \\
\hline & $(0.001)$ & $(0.003)$ & $(0.001)$ & $(0.002)$ \\
\hline \multirow[t]{2}{*}{$(\text { Employees })^{2}$} & $-266^{* * *}$ & $-72^{*}$ & $-314^{* * *}$ & $-45^{* * *}$ \\
\hline & $(84)$ & $(37)$ & $(84)$ & $(9)$ \\
\hline \multirow[t]{2}{*}{$(\text { Gross output })^{2}$} & -0.0004 & 0.0005 & 0.0001 & 0.0001 \\
\hline & -0.0003 & -0.0006 & -0.0001 & -0.0001 \\
\hline \multirow[t]{2}{*}{$\left(\right.$ Average wage rate $\left.{ }^{2}\right)$} & $-9 * * *$ & $-10^{* * *}$ & $-7 * *$ & $-9 * * *$ \\
\hline & $(3)$ & $(3)$ & $(3)$ & $(3)$ \\
\hline \multirow[t]{2}{*}{$(\text { Export share of output })^{2}$} & $-1.39^{*}$ & -0.92 & $-1.61^{* *}$ & -1.01 \\
\hline & $(0.72)$ & $(0.58)$ & $(0.8)$ & $(0.62)$ \\
\hline Sector fixed effects & yes & yes & yes & yes \\
\hline Region fixed effects & yes & yes & yes & yes \\
\hline$N$ & 2,893 & 25,269 & 2,499 & 21,817 \\
\hline
\end{tabular}

Note: All covariates in 2003 logs. Parameters for $\mathrm{CO}_{2}$ emissions, employees, gross output, and the average wage rate are in 10 million, parameters for the corresponding squared terms are in 10 billion. Standard errors in parenthesis. ${ }^{* * *} \mathrm{p}<0.01,{ }^{* *} \mathrm{p}<0.05,{ }^{*} \mathrm{p}<0.1$. Source: Research Data Centres of the Federal Statistical Office and the Statistical Offices of the Länder (2012): AFiD-Panel Industriebetriebe, 1998-2010, own calculations. 
Table C.2: Differential impact of pre-treatment fluctuations

\begin{tabular}{ccccc}
$(1)$ & $(2)$ & $(3)$ & $(4)$ & $(5)$ \\
Estimation Algorithm & \multicolumn{2}{c}{ Number of } \\
NN (1:1) & NN (1:20) & OLS w/R & Treated & Controls \\
\hline
\end{tabular}

A. Gross output: $\Delta \ln (G O)$

\begin{tabular}{cccccc}
$2001-2002$ & -0.03 & -0.01 & 0.00 & 371 & 15,362 \\
& $(0.04)$ & $(0.01)$ & $(0.01)$ & & \\
$2001-2004$ & 0.03 & 0.03 & 0.02 & 352 & 13,126 \\
& $(0.06)$ & $(0.02)$ & $(0.02)$ & & \\
\hline
\end{tabular}

B. Employment: $\Delta \ln (L)$

$\begin{array}{cccccc}2001-2002 & -0.01 & 0.00 & 0.00 & 372 & 15,367 \\ & (0.03) & (0.01) & (0.01) & & \\ 2001-2004 & 0.01 & -0.01 & -0.01 & 352 & 13,129 \\ & (0.04) & (0.01) & (0.01) & & \end{array}$

Notes: Matching covariates are from 1999. Number of firms is for nearest neighbor matching. Double-robust reweighting covers more firms because control firms outside the region of common support are included as well. Standard errors in parenthesis. ${ }^{* * *} p<0.01,{ }^{* *} p<0.05,{ }^{*} p<0.1$. Source: Research Data Centres of the Federal Statistical Office and the Statistical Offices of the Länder (2012): AFiD-Panel Industriebetriebe, 1999-2010, own calculations.

Figure C.2: Allowance price over time

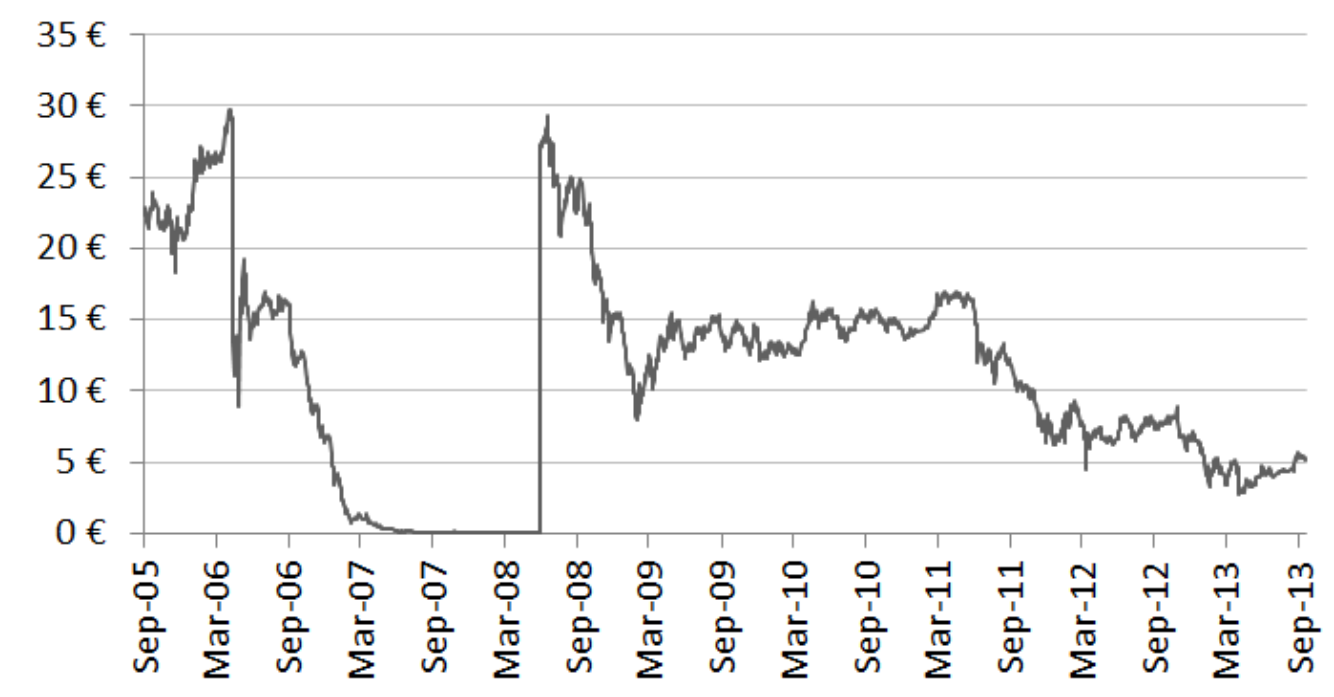

Notes: The figure plots historic spot market prices of EU Allowances (EUAs).

Source: Point Carbon (2005-2014), own representation. 
Table C.3: Baseline specification with matching on 1999 covariates

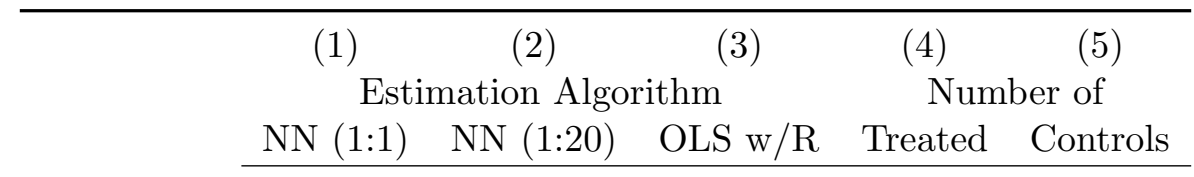

A. $\mathrm{CO}_{2}$ emissions: $\Delta \ln (C O 2)$

\begin{tabular}{cccccc} 
Phase I & 0.00 & 0.01 & $0.08^{* * *}$ & 379 & 21,418 \\
& $(0.04)$ & $(0.02)$ & $(0.03)$ & & \\
Phase II & $-0.21^{* *}$ & $-0.22^{* *}$ & $-0.27^{* *}$ & 351 & 19,071 \\
& $(0.05)$ & $(0.04)$ & $(0.04)$ & & \\
\hline
\end{tabular}

B. $\mathrm{CO}_{2}$ intensity of gross output: $\Delta \ln (C O 2 / G O)$

\begin{tabular}{cccccc} 
Phase I & -0.03 & -0.01 & $0.06^{*}$ & 379 & 21,436 \\
& $(0.04)$ & $(0.03)$ & $(0.04)$ & & \\
Phase II & $-0.30^{* *}$ & $-0.26^{* *}$ & $-0.33^{* *}$ & 354 & 19,088 \\
& $(0.05)$ & $(0.04)$ & $(0.04)$ & & \\
\hline
\end{tabular}

C. Employment: $\Delta \ln (L)$

\begin{tabular}{cccccc} 
Phase I & 0.02 & 0.00 & $0.03^{* *}$ & 381 & 22,173 \\
& $(0.02)$ & $(0.01)$ & $(0.01)$ & & \\
Phase II & 0.02 & 0.02 & 0.01 & 371 & 19,368 \\
& $(0.02)$ & $(0.01)$ & $(0.01)$ & & \\
\hline
\end{tabular}

D. Gross output: $\Delta \ln (G O)$

\begin{tabular}{cccccc} 
Phase I & $0.06^{* *}$ & $0.04^{*}$ & $0.07^{* * *}$ & 376 & 22,163 \\
& $(0.03)$ & $(0.02)$ & $(0.02)$ & & \\
Phase II & $0.07^{* *}$ & $0.05^{* *}$ & $0.05^{* * *}$ & & \\
& $(0.03)$ & $(0.02)$ & $(0.02)$ & 369 & 19,328 \\
\hline
\end{tabular}

E. Exports: $\Delta \ln (X)$

$\begin{array}{lccccc}\text { Phase I } & 0.20^{* * *} & 0.15^{* * *} & 0.20^{* * *} & 320 & 14,654 \\ & (0.07) & (0.05) & (0.05) & & \\ \text { Phase II } & 0.11^{*} & 0.11^{* *} & 0.06^{*} & 319 & 13,675 \\ & (0.07) & (0.05) & (0.04) & & \end{array}$

Notes: Matching covariates are from 1999. NN(1:1) and NN(1:20) denote nearest neighbor matching with one and 20 neighbors, respectively. OLS w/R denotes the reweighted OLS estimator. Standard errors in parenthesis. $p<0.01,{ }^{* *} p<0.05,{ }^{*} p<0.1$. Source: Research Data Centres of the Federal Statistical Office and the Statistical Offices of the Länder (2012): AFiD-Panel Industriebetriebe, 1998-2010, own calculations. 
Table C.4: Coarse matching on $\frac{C O_{2}}{L}$ and 2-digit sector. Base year 2003

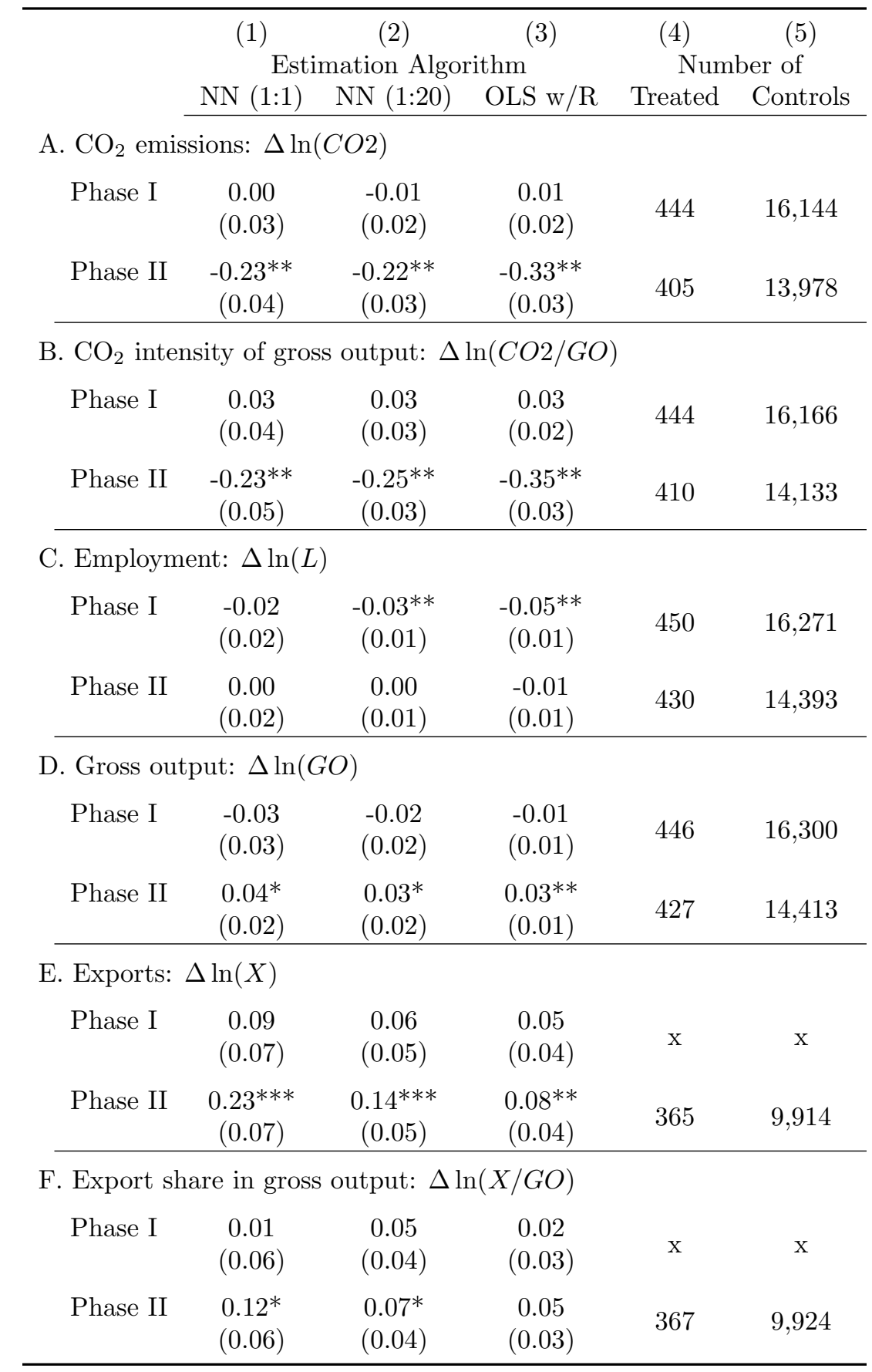

Notes: Matching covariates are from 2003. $\mathrm{NN}(1: 1)$ and $\mathrm{NN}(1: 20)$ denote nearest neighbor matching with one and 20 neighbors, respectively. OLS w/R denotes the reweighted OLS estimator. $\mathrm{x}$ : Number not cleared for reasons of privacy protection. NN matching for 2005-2007 for outcome variable carbon intensity: 10 treated off common support. NN matching for 2008-2010 for outcome variable exports: 1 treated off common support. Standard errors in parenthesis. ${ }^{* * *} p<0.01,{ }^{* *} p<0.05,{ }^{*} p<0.1$. Source: Research Data Centres of the Federal Statistical Office and the Statistical Offices of the Länder (2012): AFiD-Panel Industriebetriebe, 1998-2010, own calculations. 
Table C.5: Impact on $\mathrm{CO}_{2}$ emissions: Process-regulated sectors and other sectors

\begin{tabular}{|c|c|c|c|c|c|}
\hline & \multirow{2}{*}{\multicolumn{3}{|c|}{ Estimation Algorithm }} & $(4)$ & $(5)$ \\
\hline & & & & \multicolumn{2}{|c|}{ Number of } \\
\hline & NN $(1: 1)$ & $\mathrm{NN}(1: 20)$ & OLS w/R & Treated & Controls \\
\hline \multicolumn{6}{|c|}{ A. $\mathrm{CO}_{2}$ emissions from process-regulated sectors: $\Delta \ln \left(\mathrm{CO}_{2}\right)$} \\
\hline Phase I & $\begin{array}{l}0.08^{*} \\
(0.04)\end{array}$ & $\begin{array}{c}0.05 \\
(0.03)\end{array}$ & $\begin{array}{c}0.07^{* *} \\
(0.03)\end{array}$ & 264 & 2,629 \\
\hline Phase II & $\begin{array}{c}-0.33^{* *} \\
(0.06)\end{array}$ & $\begin{array}{c}-0.27^{* *} \\
(0.05) \\
\end{array}$ & $\begin{array}{c}-0.28^{* *} \\
(0.04) \\
\end{array}$ & 237 & 2,262 \\
\hline \multicolumn{6}{|c|}{ B. $\mathrm{CO}_{2}$ emissions from other sectors: $\Delta \ln \left(\mathrm{CO}_{2}\right)$} \\
\hline Phase I & $\begin{array}{c}-0.10^{*} \\
(0.05)\end{array}$ & $\begin{array}{c}0.00 \\
(0.03)\end{array}$ & $\begin{array}{c}-0.08^{* *} \\
(0.04)\end{array}$ & 188 & 25,081 \\
\hline Phase II & $\begin{array}{c}-0.22^{* *} \\
(0.07)\end{array}$ & $\begin{array}{c}-0.21^{* *} \\
(0.04)\end{array}$ & $\begin{array}{c}-0.20^{* *} \\
(0.04)\end{array}$ & 171 & 21,646 \\
\hline \multicolumn{6}{|c|}{ C. $\mathrm{CO}_{2}$ intensity of output from process-regulated sectors: $\ln \left(\mathrm{CO}_{2} / G O\right)$} \\
\hline Phase I & $\begin{array}{c}0.04 \\
(0.04)\end{array}$ & $\begin{array}{c}0.03 \\
(0.03)\end{array}$ & $\begin{array}{c}0.03 \\
(0.02)\end{array}$ & 265 & 2,627 \\
\hline Phase II & $\begin{array}{c}-0.36^{* *} \\
(0.06)\end{array}$ & $\begin{array}{c}-0.34^{* *} \\
(0.05)\end{array}$ & $\begin{array}{c}-0.34^{* *} \\
(0.04)\end{array}$ & 242 & 2,265 \\
\hline
\end{tabular}

D. $\mathrm{CO}_{2}$ intensity of output from other sectors: $\ln \left(\mathrm{CO}_{2} / G O\right)$

$\begin{array}{cccccc}\text { Phase I } & -0.04 & 0.00 & 0.03 & 187 & 25,105 \\ & (0.06) & (0.04) & (0.04) & & \\ \text { Phase II } & -0.23^{* *} & -0.21^{* *} & -0.25^{* *} & 171 & 21,642 \\ & (0.07) & (0.05) & (0.06) & & \end{array}$

Notes: $\mathrm{NN}(1: 1)$ and $\mathrm{NN}(1: 20)$ denote nearest neighbor matching with one and 20 neighbors, respectively. OLS $\mathrm{w} / \mathrm{R}$ denotes the reweighted OLS estimator. $p<0.01,{ }^{* *} p<0.05,{ }^{*} p<0.1$. Source: Research Data Centres of the Federal Statistical Office and the Statistical Offices of the Länder (2012): AFiD-Panel Industriebetriebe, 1998-2010, own calculations. 
Table C.6: Impact on Investment

\begin{tabular}{cccccc}
\hline \multicolumn{7}{c}{$(1)$} & \multicolumn{2}{c}{$(2)$} & $(3)$ & \multicolumn{2}{c}{$(4)$} & $(5)$ \\
\multicolumn{5}{c}{ Estimation Algorithm } & \multicolumn{2}{c}{ Number of } \\
A. Investment: & $\Delta \ln (I)$ & & & \\
NN $(1: 1)$ & NN $(1: 20)$ & OLS w/R & Treated & Controls \\
\cline { 2 - 6 } Phase I & -0.09 & -0.08 & -0.05 & 420 & 21,723 \\
& $(0.12)$ & $(0.09)$ & $(0.07)$ & & \\
Phase II & 0.03 & 0.05 & 0.04 & 397 & 18,850 \\
& $(0.12)$ & $(0.09)$ & $(0.08)$ & & \\
\hline B. Gross Investment: $\Delta \ln (G I)$ & & & \\
Phase I & -0.06 & -0.07 & -0.03 & 426 & 22,799 \\
& $(0.12)$ & $(0.08)$ & $(0.07)$ & & \\
Phase II & -0.17 & 0.00 & 0.00 & 407 & 19,764 \\
& $(0.12)$ & $(0.09)$ & $(0.08)$ & & \\
\hline
\end{tabular}

Notes: $\mathrm{NN}(1: 1)$ and $\mathrm{NN}(1: 20)$ denote nearest neighbor matching with one and 20 neighbors, respectively. OLS $\mathrm{w} / \mathrm{R}$ denotes the reweighted OLS estimator. Standard errors in parenthesis. ${ }^{* * *} \mathrm{p}<0.01,{ }^{* *} \mathrm{p}<0.05,{ }^{*} \mathrm{p}<0.1$. Source: Research Data Centres of the Federal Statistical Office and the Statistical Offices of the Länder (2012): AFiD-Panel Industriebetriebe, 1998-2010, own calculations. 
Table C.7: Impact on export share in gross output $\Delta \ln (X / G O)$

\begin{tabular}{|c|c|c|c|c|c|}
\hline & (1) & $(2)$ & $(3)$ & $(4)$ & $(5)$ \\
\hline & \multicolumn{3}{|c|}{ Estimation Algorithm } & \multicolumn{2}{|c|}{ Number of } \\
\hline & $\mathrm{NN}(1: 1)$ & $\mathrm{NN}(1: 20)$ & OLS w/R & Treated & Controls \\
\hline \multicolumn{6}{|c|}{ A. Matching based on covariates in 2003 (baseline specification) } \\
\hline Phase I & $\begin{array}{c}0.05 \\
(0.05)\end{array}$ & $\begin{array}{c}0.06 \\
(0.04)\end{array}$ & $\begin{array}{c}0.07^{* *} \\
(0.03)\end{array}$ & 378 & 18,184 \\
\hline Phase II & $\begin{array}{c}0.05 \\
(0.06)\end{array}$ & $\begin{array}{c}0.06 \\
(0.04)\end{array}$ & $\begin{array}{c}0.03 \\
(0.04)\end{array}$ & 371 & 16,635 \\
\hline \multicolumn{6}{|c|}{ B. Matching based on covariates in 1999} \\
\hline Phase I & $\begin{array}{l}0.10^{*} \\
(0.06)\end{array}$ & $\begin{array}{c}0.07 \\
(0.04)\end{array}$ & $\begin{array}{c}0.11^{* * *} \\
(0.04)\end{array}$ & 321 & 14,652 \\
\hline Phase II & $\begin{array}{c}0.03 \\
(0.07) \\
\end{array}$ & $\begin{array}{c}0.05 \\
(0.04) \\
\end{array}$ & $\begin{array}{c}0.01 \\
(0.03) \\
\end{array}$ & 321 & 13,670 \\
\hline \multicolumn{6}{|c|}{ C. Coarse matching on $C \mathrm{O}_{2} / L$ in 2003} \\
\hline Phase I & $\begin{array}{c}0.01 \\
(0.06)\end{array}$ & $\begin{array}{c}0.05 \\
(0.04)\end{array}$ & $\begin{array}{c}0.02 \\
(0.03)\end{array}$ & $\mathrm{x}$ & $\mathrm{x}$ \\
\hline Phase II & $\begin{array}{c}0.12^{*} \\
(0.06)\end{array}$ & $\begin{array}{c}0.07^{*} \\
(0.04)\end{array}$ & $\begin{array}{c}0.05 \\
(0.03)\end{array}$ & 367 & 9,924 \\
\hline
\end{tabular}

Notes: $\mathrm{NN}(1: 1)$ and $\mathrm{NN}(1: 20)$ denote nearest neighbor matching with one and 20 neighbors, respectively. OLS w/R denotes the reweighted OLS estimator. Standard errors in parenthesis. ${ }^{* * *} p<0.01,{ }^{* *} p<0.05,{ }^{*} p<0.1$.

Source: Research Data Centres of the Federal Statistical Office and the Statistical Offices of the Länder (2012): AFiD-Panel Industriebetriebe, 1998-2010, own calculations. 